\title{
¿Isopycnal Mixing Suppression by the Antarctic Circumpolar Current and the Southern Ocean Meridional Overturning Circulation
}

\author{
CHRISTOPHER CHAPMAN AND JEAN-BAPTISTE SALLÉE \\ LOCEAN-IPSL, Paris, France
}

(Manuscript received 2 December 2016, in final form 19 April 2017)

\begin{abstract}
The meridional overturning circulation (MOC) in the Southern Ocean is investigated using hydrographic observations combined with satellite measurements of sea surface height. A three-dimensional (spatial and vertical) estimate of the isopycnal eddy diffusivity in the Southern Ocean is obtained using the theory of Ferrari and Nikurashin that includes the influence of suppression of the diffusivity by the strong, time-mean flows. It is found that the eddy diffusivity is enhanced at depth, reaching a maximum at the critical layer near $1000 \mathrm{~m}$. The estimate of diffusivity is used with a simple diffusive parameterization to estimate the meridional eddy volume flux. This estimate of eddy volume flux is combined with an estimate of the Ekman transport to reconstruct the time-mean overturning circulation. By comparing the reconstruction with, and without, suppression of the eddy diffusivity by the mean flow, the influence of the suppression on the overturning is illuminated. It is shown that the suppression of the eddy diffusivity results in a large reduction of interior eddy transports and a more realistic eddy-induced overturning circulation. Finally, a simple conceptual model is used to show that the MOC is influenced not only by the existence of enhanced diffusivity at depth but also by the details of the vertical structure of the eddy diffusivity, such as the depth of the critical layer.
\end{abstract}

\section{Introduction}

The meridional overturning circulation (MOC) is a global-scale circulation that, due to its important role in the redistribution of heat, salt, and biogeochemical tracers from warmer to colder latitudes and the subduction of atmospheric $\mathrm{CO}_{2}$, has a large influence on the climate system (Talley et al. 2003; Marshall and Speer 2012). In the Southern Ocean, the overturning is related to the rate that deep carbon-rich waters are ventilated at the surface where they can communicate with the atmosphere and the rate at which surface waters are in turn subducted into the ocean interior (Sallée et al. 2013). Thus, changes in the rate of the overturning have been hypothesized to lead to a reduction in the Southern Ocean's ability to absorb and sequester $\mathrm{CO}_{2}$ (Le Quéré et al. 2007). Understanding the dynamic controls of the MOC in the Southern

¿ Denotes content that is immediately available upon publication as open access.

Corresponding author: Christopher Chapman, chris.chapman. 28@gmail.com
Ocean as well as how it will respond to external changes in the climate system is therefore a pressing question in physical oceanography.

Motivated by the widely acknowledged importance of the Southern Ocean for the global MOC, intense focus on this region has led to significant advances in our understanding of the structure of the MOC and dominant dynamical mechanisms that lead to its formation. In particular, a description of the Southern Ocean based on the transformed Eulerian-mean (TEM) formulation has shown that, on the large scale, the Southern Ocean overturning results from a competition between a northward, wind-driven, Eulerian-mean overturning cell $\bar{\Psi}$ and a southward, eddy-induced overturning $\Psi^{\star}$, where $\Psi$ is the overturning streamfunction (Johnson and Bryden 1989; Döös and Webb 1994). The mean and eddy-induced overturning are thought to be of similar magnitude, yet opposite sign, such that only a small residual transport remains. The resulting overturning, commonly expressed as an overturning streamfunction, is written as

$$
\Psi^{\mathrm{res}}=\bar{\Psi}+\Psi^{\star} \text {. }
$$

Because of the delicate balance between the eddy and mean overturning, the residual overturning is sensitive 
to even small changes in one or the other component resulting from changes in surface forcing (Abernathey et al. 2011; Meredith et al. 2012; Downes and Hogg 2013).

The Southern Ocean also hosts the Antarctic Circumpolar Current (ACC), a system of currents that are among strongest on Earth. Although the ACC is primarily zonally oriented, it has direct and indirect roles in shaping the Southern Ocean MOC. For instance, the interaction of the ACC with bathymetry results in a significant geostrophic interior overturning circulation that results from pressure gradients associated with isopycnal outcropping. This geostrophic flux is distinct from the mean ageostrophic overturning associated with Ekman currents (MacCready and Rhines 2001; Mazloff 2008; Mazloff et al. 2013). In addition, the ACC has a strong influence on the mixing ability of mesoscale eddies and hence the ability to move water poleward (Bates et al. 2014). The capacity of eddies to induce a downgradient flux is often measured by the eddy diffusivity $K$, which relates the eddy flux of some tracer with concentration $C$ to the large-scale gradient of that tracer:

$$
\overline{\mathbf{u}^{\prime} C^{\prime}}=\mathbf{K} \cdot \nabla C,
$$

where $\mathbf{K}$ is the diffusivity tensor, $\mathbf{u}=(\mathrm{u}, v)$ is the horizontal velocity vector, and the primes denote perturbations from the time mean. Although baroclinic eddies are ubiquitous in the Southern Ocean, certain regions, referred to as hot spots or storm tracks, which arise from the interaction of the ACC with bathymetry (Williams et al. 2007; Chapman et al. 2015), cause localized increases in $K$ (Sallée et al. 2008). The ACC also modulates the vertical structure of eddy diffusivity, which is known to be enhanced at depth, reaching a maxima at the steering level or critical layer depth (Ferrari and Nikurashin 2010; Abernathey et al. 2010) associated with the fastest growing linear waves (Smith and Marshall 2009). Linear stability analysis places this level at around 1000-m depth (Smith and Marshall 2009). Although it has been shown that including a spatially varying $K$ can reduce bias in coarse-resolution climate models (Ferreira et al. 2005; Danabasoglu and Marshall 2007) and while the implications of a three-dimensional $K$ on the broad-scale flow have been briefly discussed in several studies (Marshall et al. 2006; Shuckburgh et al. 2009; Smith and Marshall 2009; Naveira Garabato et al. 2011; Bates et al. 2014), a detailed understanding of the physical implications of three-dimensionally varying $K$ for the large-scale overturning circulation is still lacking.

In this study, we seek to characterize and quantify the influence of storm tracks and the suppression of the eddy diffusivity by the mean flow on the Southern Ocean overturning circulation. We will explore the impact of geostrophic mean flow on the MOC, and in particular the impact of the strong currents of the ACC in modulating the eddy overturning. To achieve our goals, we reconstruct the overturning circulation from a large observational dataset that combines hydrographic data from Argo floats, oceanographic cruises, and instrumented elephant seals, with sea surface height altimetry. The observational datasets are used to develop a direct estimate of the Eulerian-mean overturning due to ageostrophic Ekman currents. In addition, we produce a three-dimensional estimate of $K$ based on the theory of Ferrari and Nikurashin (2010) that allows a reconstruction of an eddy overturning streamfunction from the downgradient diffusion of potential vorticity (Treguier et al. 1997). We will investigate the influence of spatial variation of $K$ and the suppressing influence of the background flow on the reconstructed eddy and residual streamfunctions. By reconstructing $\Psi^{\star}$ from observations, we show that this mixing suppression has a significant impact on the eddy overturning and therefore plays a key role in shaping the residual overturning circulation. In tandem with this reconstruction, we employ a simple conceptual model, based on the TEM approach of Marshall and Radko (2003, 2006), to guide our interpretation of the observational-based reconstruction.

The remainder of this paper is organized as follows: The theoretical framework used for building the reconstruction of the MOC from observations, including the procedure for estimating the horizontal (isopycnal) diffusivity $K$, will be presented in section 2 . The observational dataset we employ will be described in section 3. Our estimate of the threedimensional eddy diffusivity will be presented in section 4, and our estimated MOC reconstruction, along with a comparison of the results obtained with and without the influence of the background flow in section 5 . The influence of a vertically varying $K$ on the overturning will then be elucidated using a conceptual model in section 6 . Finally, we will bring together the observational and theoretical results of this study in section 7 .

\section{The Southern Ocean meridional overturning circulation}

Here, we briefly revise the basic theory of the MOC in the Southern Ocean, the theory of mean flow suppression of eddy diffusivity, and the formulation of the TEM model equations. It is important to state at the beginning that this analysis is conducted in streamwise coordinates, as in Marshall and Radko (2003). In this 
coordinate system the "meridional" coordinate $\eta$ is in fact the across-stream direction, while the "zonal" coordinate $s$ is in the along-stream direction. All zonal averages are taken to be along streamlines, as in de Szoeke and Levine (1981). The technical details of this coordinate transform are described in Viebahn and Eden (2010), while its influence on the resulting overturning are discussed in Treguier et al. (2007). For clarity, in the following discussion, we will use the notation $s$ and $\eta$ as zonal and meridional stream coordinates, in place of the usual $x$ and $y$ notation used in the majority of the literature (e.g., Marshall and Radko 2003).

On an isopycnal surface $\gamma$, with thickness $h=-\partial z / \partial \gamma$, the time-mean meridional volume flux is given by

$$
\overline{h v}=\bar{h} \bar{v}+\overline{h^{\prime} v^{\prime}}
$$

where $v=\mathbf{u} \cdot \mathbf{e}_{\eta}$ is the cross-stream velocity, $\mathbf{e}_{\eta}$ is the unit vector in the across-stream direction, and $\overline{(\cdot)}$ is the timeaveraging operator. The primed quantities are perturbations from the time mean, such that $v=\bar{v}+v^{\prime}$ and $\overline{v^{\prime}}=0$. We can further decompose $v$ into geostrophic $v_{g}$ and ageostrophic $v_{\mathrm{ag}}$ components, giving

$$
\overline{h v}=\bar{h} \overline{v_{g}}+\bar{h} \overline{v_{\mathrm{ag}}}+\overline{h^{\prime} v_{g}^{\prime}}+\overline{h^{\prime} v_{\mathrm{ag}}^{\prime}} .
$$

The meridional transport can then be vertically integrated over the isopycnal surfaces and zonally around the circumpolar path to determine the time-mean, zonally integrated, isopycnal overturning streamfunction (Döös and Webb 1994):

$$
\Psi^{\mathrm{res}}(\eta, \gamma)=\oint \int_{0}^{\gamma} \overline{h v} d \gamma^{\prime} d s=\underbrace{\bar{\Psi}_{\mathrm{ag}}+\bar{\Psi}_{g}}_{\text {mean }}+\underbrace{\Psi_{g}^{\star}+\Psi_{\mathrm{ag}}^{\star}}_{\text {eddy }} .
$$

\section{a. The ageostrophic transport}

In the Southern Ocean, the overwhelming majority of the ageostrophic transport $\bar{h} \bar{v}_{\text {ag }}$ occurs due to surface Ekman currents. The ageostrophic eddy transport $\overline{h^{\prime} v_{\mathrm{ag}}^{\prime}}$, although not completely negligible, is much smaller than the time-mean Ekman transport (Mazloff et al. 2013). Since we are unable to estimate this term from the data used in this study, we will not discuss it further, although, for reference, Mazloff et al. (2013) find a southward transport of approximately $5 \mathrm{~Sv}\left(1 \mathrm{~Sv} \equiv 10^{6} \mathrm{~m}^{3} \mathrm{~s}^{-1}\right)$ contained almost entirely in the surface layers. The time-mean Ekman velocity can be determined from the surface wind stress using the equations for an Ekman spiral (Dutton 1986, p. 449):

$$
\begin{aligned}
u_{\mathrm{ag}}= & \frac{\sqrt{2}}{\rho_{0} f h_{\text {Ekman }}} e^{z / h_{\text {Ekman }}}\left[\tau^{x} \cos \left(\frac{z}{h_{\text {Ekman }}}-\frac{\pi}{4}\right)\right. \\
& \left.-\tau^{y} \sin \left(\frac{z}{h_{\text {Ekman }}}-\frac{\pi}{4}\right)\right], \text { and } \\
v_{\mathrm{ag}}= & \frac{\sqrt{2}}{\rho_{0} f h_{\text {Ekman }}} e^{z / h_{\text {Ekman }}}\left[\tau^{x} \sin \left(\frac{z}{h_{\text {Ekman }}}-\frac{\pi}{4}\right)\right. \\
& \left.-\tau^{y} \cos \left(\frac{z}{h_{\text {Ekman }}}-\frac{\pi}{4}\right)\right],
\end{aligned}
$$

where $\tau^{x}$ and $\tau^{y}$ are the zonal and meridional components of the surface wind stress; $z$ is the vertical coordinate; $f=2 \Omega_{E} \sin \phi$ is the Coriolis parameter, where $\Omega_{E}$ is Earth's rotation rate and $\phi$ is the latitude; $\rho_{0}$ is a constant reference density; and $h_{\text {Ekman }}$ is a constant Ekman layer depth, here taken to be $100 \mathrm{~m}$, which is consistent with observations in the Southern Ocean (Lenn and Chereskin 2009). However, we note that the primary quantity of interest here, the Ekman-induced overturning streamfunction, can be written as $\Psi^{\mathrm{Ekman}}=\tau / f_{0}$ and hence is independent of the details of the Ekman layer. Once determined, the zonal and meridional Ekman velocities are then resolved into along- and across-stream components, which are then used to determine the time-mean component of the overturning.

\section{b. Time-mean geostrophic transport}

The time-mean geostrophic transport $\bar{h} \bar{v}_{g}$ can be determined from hydrography by computing the dynamic height anomaly, which is equivalent to a geostrophic streamfunction. However, on an isopycnal layer no exact geostrophic streamfunction exists (McDougall 1989). McDougall and Klocker (2010) have formulated an approximate streamfunction on a neutral density surface (Jackett and McDougall 1997) that takes into account the nonlinearity of the equation of state and can be computed from hydrography. The geostrophic velocities are then related to the streamfunction $M$ by the geostrophic balance relation:

$$
f \mathbf{u}_{g}=\mathbf{k} \times \nabla M,
$$

where $\mathbf{k}$ is the unit vector in the vertical direction. The meridional geostrophic transport $h v_{g}$ does not necessarily integrate to zero around a circumpolar circuit because of outcropping of the isopycnals with either the surface or with topography (Koh and Plumb 2004; Ward and Hogg 2011; Mazloff et al. 2013) or because if a non-depthdependent pathway is chosen to define the streamwise coordinate system, the fact that the Southern Ocean is not perfectly equivalent barotropic means that flow at depth can be misaligned with the chosen coordinate system, which can support a small but nonzero cross-stream flux (Viebahn and Eden 2012; Dufour et al. 2015). 


\section{c. Geostrophic eddy transport}

The geostrophic eddy transport $\overline{h^{\prime} v_{g}^{\prime}}$ is also found to be of first-order importance in a number of studies (Abernathey et al. 2011; Mazloff et al. 2013; Dufour et al. 2015). However, we are unable to estimate this term directly from observations, and hence it must be parameterized. Following Marshall et al. (1999), we start by noting that the geostrophic eddy flux of Ertel potential vorticity $(\mathrm{PV}) q=(f+\zeta) / h$ can be written as

$$
\overline{v_{g}^{\prime} q^{\prime}}=-\frac{f}{\bar{h}^{2}} \overline{h^{\prime} v_{g}^{\prime}}
$$

where $\zeta=\partial v / \partial x-\partial u / \partial y$ is the vertical relative vorticity, and assuming planetary geostrophic scaling such that $q \approx f / h$ and $h^{\prime} / \bar{h} \ll 1$. Thus, the geostrophic eddy volume flux can be written as

$$
\overline{h^{\prime} v_{g}^{\prime}}=-\frac{\bar{h}}{\bar{q}} \overline{v_{g}^{\prime} q^{\prime}} .
$$

We now employ the simple downgradient diffusive closure for $\overline{v_{g}^{\prime} q^{\prime}} \approx K \partial \bar{q} / \partial \eta$, described in detail by Treguier et al. (1997) and discussed in numerous papers thereafter (Killworth 1997; Marshall et al. 1999; Wardle and Marshall 2000; Roberts and Marshall 2000; Wilson and Williams 2004; Plumb and Ferrari 2005) to give

$$
\overline{h^{\prime} v_{g}^{\prime}}=-K \frac{\bar{h}}{\bar{q}} \frac{\partial \bar{q}}{\partial \eta}
$$

Equation (11) is a crude parameterization of the true eddy fluxes with numerous failings (Roberts and Marshall 2000; Wilson and Williams 2004). However, it has been shown to work well when one is interested only in the large-scale flow (Marshall et al. 1999; Plumb and Ferrari 2005; Kuo et al. 2005). Equation (11) is not the only possible choice of eddy closure. In fact, there are numerous diffusive closures, such as the downgradient thickness diffusion (the Gent-McWilliams parameterization; Gent and McWilliams 1990) or the quasigeostrophic PV flux. Our choice of parameterization is motivated by both dynamical and practical considerations: the planetary-scale PV gradient is well defined, provides the fluxes with the correct sign in both the surface mixed layer and the adiabatic interior (Mazloff 2008), and follows naturally from the surface quasigeostrophic equation used to formulate the eddy diffusion coefficient (see section 2d). However, Abernathey et al. (2013) have shown that most of the commonly used diffusive eddy closures yield roughly equivalent results. As such, we expect our results to hold under different closure schemes, although the details of any resulting eddy flux reconstructions may vary.

\section{d. Eddy diffusivity}

With the closure for the eddy volume flux in terms of the large-scale PV gradient, we are able to reconstruct the geostrophic eddy volume flux with knowledge of the eddy diffusivity $K$, which is known to be dependent on the eddy kinetic energy, the spatial and temporal scales of the mesoscale eddies, and on the state of the background mean flow (Smith and Marshall 2009; Abernathey et al. 2010; Ferrari and Nikurashin 2010; Klocker and Abernathey 2014; Bates et al. 2014). Ferrari and Nikurashin (2010), using the assumptions of simple isotropic turbulence modeled by a white-noise process, derived the following expression for $K$ that takes into the account the effects of the mean flow:

$$
K_{\perp}=\frac{K_{0}}{1+k_{\text {eddy }}^{2} \tau_{\text {eddy }}^{2}\left[c_{p}-\bar{u}_{s}(x, y, z)\right]^{2}},
$$

where the term $K_{0}$ represents the eddy diffusivity, which is unmodified by the mean flow; $K_{\perp}$ is the modified eddy diffusivity (sometimes called the effective diffusivity or the suppressed diffusivity for reasons that will soon become apparent) across the mean streamlines; $k_{\text {eddy }}$ is the zonal eddy wavenumber; $\tau_{\text {eddy }}$ is the eddy decorrelation time scale; $c_{p}$ is the eddy phase speed; $\bar{u}_{s}=\overline{\mathbf{u}} \cdot \mathbf{e}_{s}$ is the time-mean, along-stream velocity; and $\mathbf{e}_{s}$ is the unit vector in the along-stream direction.

As $\bar{u}_{s} \rightarrow c_{p}$, the denominator of Eq. (12) approaches unity, which means that $K_{\perp} \rightarrow K_{0}$. In the case where $\bar{u}_{s} \neq c_{p}$, the denominator of Eq. (12) is greater than unity and $K_{\perp}<K_{0}$. For this reason, the denominator of Eq. (12) is called the suppression factor (Klocker and Abernathey 2014). This reaches its minima at the critical level, that is, where $\bar{u}=c_{p}$, which is thought to lie at about $1000 \mathrm{~m}$ of depth (Smith and Marshall 2009). The suppression factor also varies throughout the Southern Ocean; tracer diffusivity is suppressed more in regions where mean currents are strong and less where they are weak (Klocker and Abernathey 2014).

With Eqs. (11) and (12), we can reconstruct the eddy component of the MOC. Investigating the role that the spatial variability and suppression of $K$ play in the MOC is the primary goal of this paper.

\section{e. Simple conceptual model of the Southern Ocean overturning}

To guide our analysis based on the observation-based reconstructed overturning, we will use a simple conceptual model, with the aim of further understanding the influence that vertically variable diffusivity has on the stratification and the overturning (section 5). 
Our model has essentially the same form as that of Marshall and Radko (2003, 2006). Specifically, we solve the time and zonally averaged TEM equations in the ocean interior:

$$
\begin{aligned}
J_{\eta z}\left(\left\langle\Psi^{\mathrm{res}}\right\rangle,\langle\bar{b}\rangle\right) & =0, \\
\left\langle\Psi^{\mathrm{res}}\right\rangle(\eta, \bar{b}) & =\langle\bar{\Psi}\rangle(\eta)+\left\langle\Psi^{\star}\right\rangle(\eta,\langle\bar{b}\rangle), \text { and } \\
\left\langle\Psi^{\star}\right\rangle & =-K \frac{\partial\langle\bar{b}\rangle}{\partial \eta} / \frac{\partial\langle\bar{b}\rangle}{\partial z},
\end{aligned}
$$

where $b=b(\eta, z)$ is the buoyancy, $J_{\eta z}$ is the Jacobian operator, $(\partial b / \partial \eta) /(\partial b / \partial z)$ is the across-stream isopycnal slope, and $\langle(\cdot)\rangle$ denotes zonal (along stream) averaging. Here, the mean overturning is taken to be simply that associated with the Ekman flow $\langle\bar{\Psi}\rangle=-\left\langle\tau^{\text {wind }}\right\rangle(\eta) / f$. Rearranging Eqs. (14) and (15) and substituting for $\bar{\Psi}$ gives

$$
\left[\frac{\left\langle\tau^{\text {wind }}\right\rangle(\eta)}{f}+\Psi^{\mathrm{res}}\right] \frac{\partial\langle b\rangle}{\partial z}+K \frac{\partial\langle b\rangle}{\partial \eta}=0 .
$$

Equation (16) can be solved numerically using the method of characteristics, as detailed in appendix B. The boundary conditions are identical to those of Marshall and Radko (2006); the buoyancy field is set at the base of the homogeneous mixed layer (here taken as $z=0$ ) and on the northern boundary:

$$
\begin{aligned}
\langle b\rangle(y, 0) & =\Delta b^{\text {surf }} \frac{\eta}{L_{\eta}}, \quad \text { and } \\
\langle b\rangle\left(L_{\eta}, z\right) & =b\left(L_{\eta}, 0\right) e^{z / h_{e}},
\end{aligned}
$$

where $L_{\eta}=2000 \mathrm{~km}$ is the meridional scale of the ACC, $h_{e}=1000 \mathrm{~m}$ is the $e$-folding depth, and $\Delta b^{\text {surf }}=$ $0.007 \mathrm{~m} \mathrm{~s}^{-2}$ is the buoyancy gain across the ACC. Additionally, the surface wind stress $\tau^{\text {wind }}(\eta)$ is taken to be a simple sinusoidal profile:

$$
\left\langle\tau^{\mathrm{wind}}\right\rangle(\eta)=\tau_{0}\left[0.3+\sin \left(\frac{\pi}{L_{\eta}} \eta\right)\right],
$$

with $\tau_{0}=1.5 \times 10^{-4} \mathrm{~N} \mathrm{~m}^{-2}$. The residual overturning streamfunction $\Psi^{\text {res }}$ is not specified as a surface boundary condition but is instead calculated as part of the solution using the iterative technique of Marshall and Radko (2006) and further described in appendix B.

\section{Observational data}

\section{a. Hydrographic data}

The primary data used for this study are approximately 250000 profiles of temperature and salinity from the surface to maximum depth of $2000 \mathrm{db}$, collected from 1956 autonomous Argo floats (Roemmich et al. 2009; Riser et al. 2016) between $80^{\circ}$ and $30^{\circ} \mathrm{S}$ of latitude from 1 January 2006 to 31 December 2014. Argo floats provide broad-scale coverage of the Southern Ocean, shown in Fig. 1a, with sufficient spatial and temporal resolution to resolve the large-scale circulation and seasonal variability. Unfortunately, the relatively large distances between observations (approximately 80$100 \mathrm{~km}$ in the Southern Ocean) and the insufficient number of temporally simultaneous measurements mean that the Argo array is not capable of directly resolving the instantaneous mesoscale. However, McCaffrey et al. (2015) and Chapman and Sallée (2017, manuscript submitted to Ocean Modell.) have shown that it is possible to use Argo floats to measure the statistics of the mesoscale turbulence.

The Argo array has a limited number of observations along the southern border of the ACC and along the seasonal sea ice edge. To supplement the Argo data, we additionally employ hydrographic profiles obtained from various research cruises, assembled in the World Ocean Database (WOD; Boyer et al. 2009) and 223426 profiles collected from 513 instrumented southern elephant seals (Roquet et al. 2013, 2014). These animals forage throughout the Southern Ocean but prioritize regions that are generally farther south of those sampled by the Argo floats. Data coverage of Argo, WOD, and the instrumented seals are shown in Fig. 1. The combined dataset samples all of the major water mass classes within the Southern Ocean, as shown in Fig. 2. This figure shows histograms of the deepest profile depth (Fig. 2a) and densest profile neutral density (Fig. 2b) sampled by each of the three data sources. The majority of Argo profiles sample to $2000 \mathrm{~m}$ and to about $\gamma=27.8 \mathrm{~kg} \mathrm{~m}^{-3}$; the majority of the instrumented seals' profiles sample to around 500-m depth, with some profiles deeper than $1000 \mathrm{~m}$ and to about $\gamma=28.0 \mathrm{~kg} \mathrm{~m}^{-3}$. We note that although waters denser than $\gamma=28.0 \mathrm{~kg} \mathrm{~m}^{-3}$ (Antarctic Bottom Water) are sampled in this dataset, the coverage is patchy, being sampled primarily in the Atlantic sector. It can be seen in Fig. $2 c$ that the addition of instrumented seals to the database significantly improves winter data coverage.

For all datasets, only profiles that have passed quality control checks are used. Additional quality control was carried out using an automated outlier detection algorithm based on an interquartile range filter and density inversion filter, as in Schmidtko et al. (2013). Data from 2006 to 2014 are used in this study, as there is insufficient data in preceding years to provide coverage of the entire Southern Ocean, as shown in Fig. 2c. 


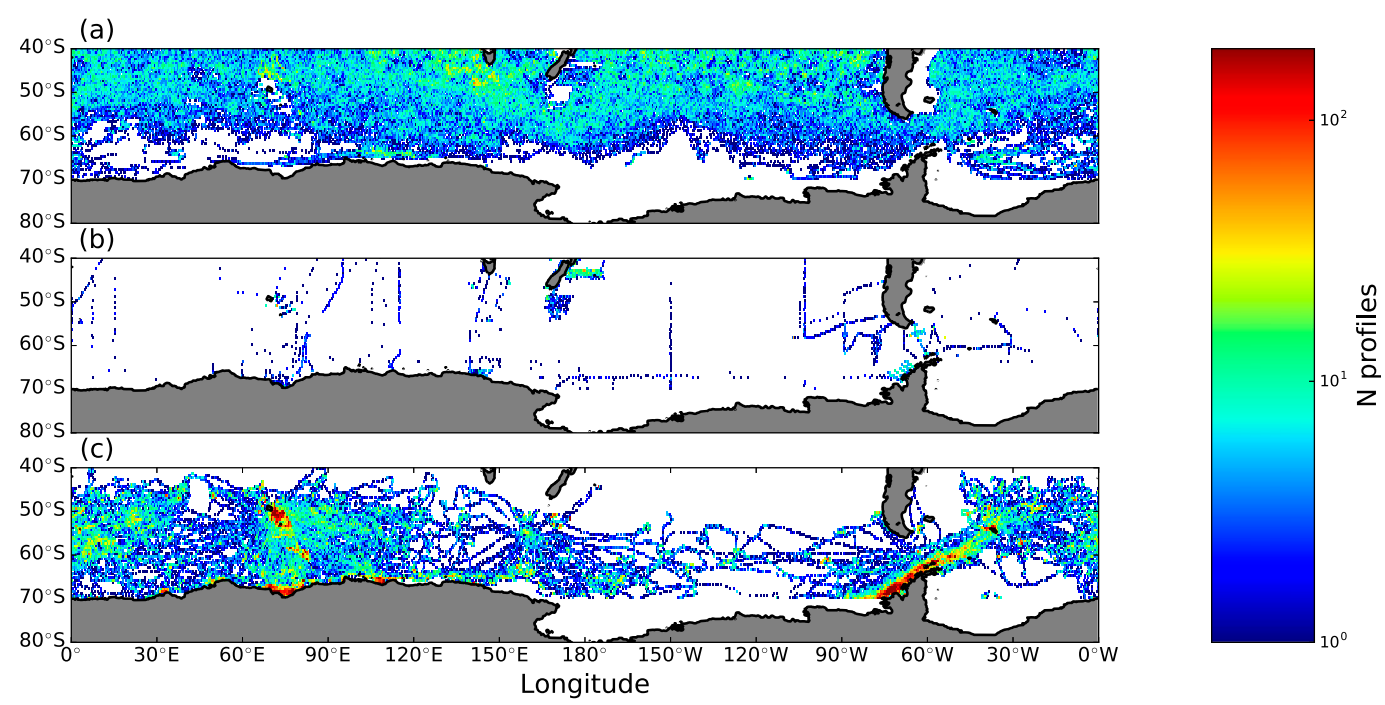

FIG. 1. Spatial distribution of hydrographic profiles in the Southern Ocean used in this study. The number of profiles in each $0.5^{\circ} \times 0.5^{\circ}$ grid box from (a) Argo, (b) ship-based WOD, and (c) instrumented elephant seals.

\section{b. Satellite data}

In addition to the hydrographic data, we also employ satellite-derived estimates of sea surface dynamic topography in order to provide a reference velocity. Here, we use the Archiving, Validation, and Interpretation of Satellite Oceanographic data (AVISO) daily gridded absolute dynamic topography (ADT) from SSALTO/ DUACS, downloaded from Copernicus Marine Services (http://marine.copernicus.eu/web/69-interactive-catalogue. php; Ssalto/Duacs 2014; Pujol et al. 2016). We use delayedmode dynamic topography provided on a $1 / 4^{\circ}$ Mercator grid, obtained by optimally interpolating the along-track data series based on the REF dataset, which uses two satellite missions [Ocean Topography Experiment (TOPEX)/Poseidon/European Remote Sensing Satellite (ERS) or Jason-1/Envisat or Jason-2/Envisat] with consistent sampling over the 21-yr period.

The AVISO ADT is then calculated at each of the hydrographic profile locations and sampling times by three-dimensional linear interpolation (i.e., spatially and temporally). Thus, for every hydrographic profile we have an associated estimate of the ADT. Profiles obtained in regions or at times where ADT data are not

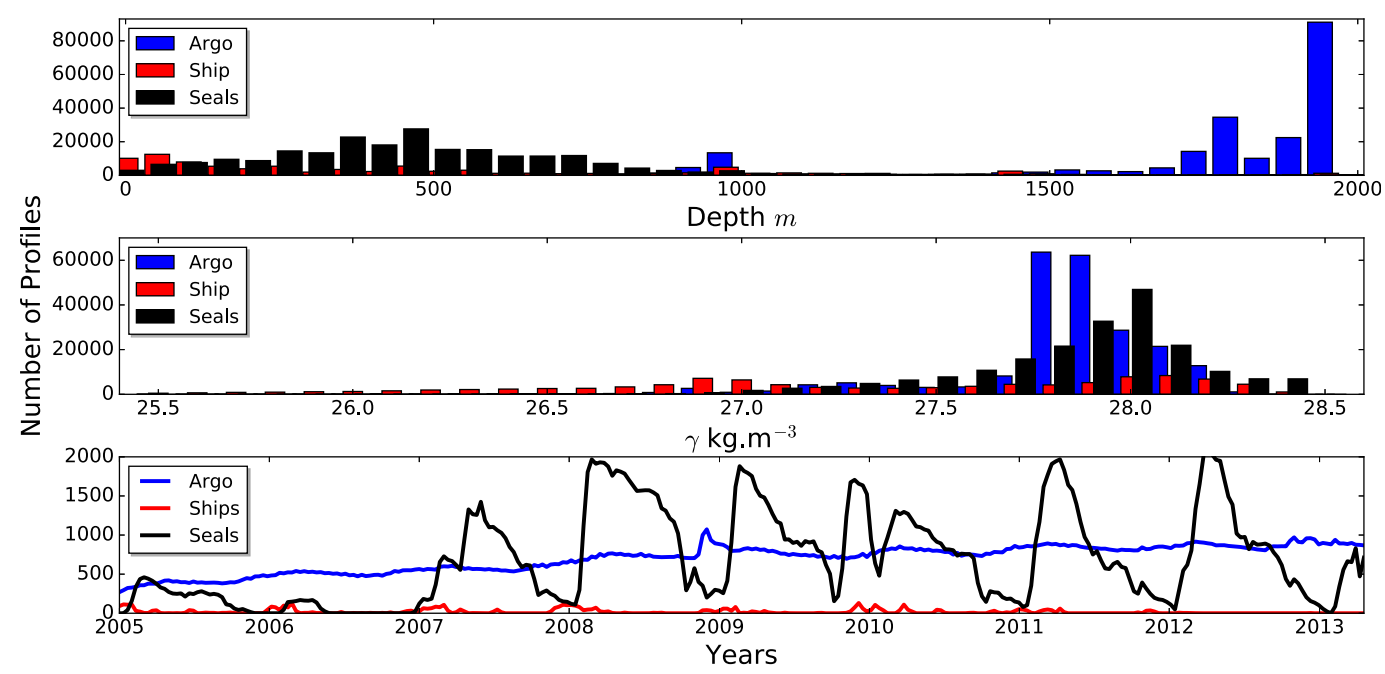

FIG. 2. Depth, density, and temporal sampling of in the hydrographic data in the Southern Ocean. (a) Histogram showing the deepest depth sampled by hydrographic profiles sourced from the Argo floats (blue), ship-based WOD (red), and instrumented elephant seals (black). (b) As in (a), but for the densest neutral density $\gamma$ sampled for each data source. (c) The number of profiles from each data source, each month, between 2005 and 2014. 
available (which occurs frequently in winter in the far south of the domain) are flagged and excluded from the analysis.

\section{c. Surface wind forcing}

To calculate the meridional circulation due to Ekman currents we use the daily mean output of surface momentum flux from the National Centers for Environmental Prediction (NCEP) reanalysis product (http://www.esrl.noaa.gov/psd/data/reanalysis/ reanalysis.shtml), described in Kalnay et al. (1996), to determine the wind stress $\tau$. Although there are substantial differences between reanalysis products over the Southern Ocean ( $\mathrm{Li}$ et al. 2013), their wind stress curls and induced Ekman currents are generally in agreement (Chien 2008). As such, we do not expect our estimates of Ekman-induced overturning to be particularly sensitive to our choice of reanalysis product.

\section{d. Climatology of the Southern Ocean}

Using the hydrographic and satellite data products described above, we develop a climatology of the Southern Ocean. In particular, from the temperature, salinity, and pressure profiles, we compute the neutral density $\gamma$, the isopycnal potential vorticity (IPV) $q$, and the absolute geostrophic streamfunction $M$.

Profiles of $\gamma$ are computed from our hydrographic database using the software described by Jackett and McDougall (1997). To compute the IPV, we make the planetary geostrophic approximation, which is a good approximation of the Ertel PV in the Southern Ocean interior (Thompson and Naveira Garabato 2014):

$$
q \approx \frac{f}{\rho_{0}} \frac{\partial \gamma}{\partial z}
$$

To compute profiles of isopycnal streamfunction, defined in McDougall and Klocker (2010) [see Eq. (8)], we use version 3 of the International Thermodynamic Equation Of Seawater-2010 (TEOS-10) software (McDougall and Barker 2011). From hydrographic data we can only obtain the relative streamfunction, that is, the streamfunction relative to some reference level $\gamma=\gamma_{\mathrm{ref}}$ :

$$
\mathbf{u}_{g_{\mathrm{rel}}}(x, y, \gamma)=\mathbf{u}_{g}(x, y, \gamma)-\mathbf{u}_{g}\left(x, y, \gamma_{\mathrm{ref}}\right)=\frac{1}{f} \mathbf{k} \times \nabla M_{\mathrm{rel}} .
$$

To determine the absolute streamfunction, we follow Kosempa and Chambers (2014) and reference our streamfunction to the surface. Since the ADT can be interpreted as the surface streamfunction

$$
\mathbf{u}_{g}\left(x, y, \gamma_{\text {surf }}\right)=\frac{g}{f} \mathbf{k} \times \nabla A D T,
$$

the absolute streamfunction is computed by adding the estimated ADT at each hydrographic profile location to the relative streamfunction referenced to the surface:

$$
M_{\mathrm{abs}}=\mathrm{ADT}+M_{\mathrm{rel}} .
$$

Finally, profiles of neutral density, IPV, and absolute geostrophic streamfunction are interpolated to a regular longitude/latitude grid using the CSIRO Atlas of Regional Seas Robust Locally Weighted Regression (CARS-LOWESS) software (Ridgway et al. 2002). The neutral density is mapped on depth surfaces from the surface to $2000 \mathrm{~m}$, with a vertical spacing of $\Delta z=50 \mathrm{~m}$. The IPV and streamfunction are mapped on a set of isopycnal layers from $\gamma=26.0$ to $28.5 \mathrm{~kg} \mathrm{~m}^{-3}$, with a vertical spacing of $\Delta \gamma=0.05 \mathrm{~kg} \mathrm{~m}^{-3}$. For consistency with the altimetric observations, we use a horizontal grid spacing of $0.25^{\circ} \times 0.25^{\circ}$, although the effective resolution of the hydrographic data is coarser (the average distance between Argo floats profile locations in the Southern Ocean is approximately $100 \mathrm{~km}$ ).

An example of our climatology is shown in Fig. 3, here for the isopycnal $\gamma=27.9 \mathrm{~kg} \mathrm{~m}^{-3}$. The depth of this isopycnal is shown in Fig. 3a, which reveals, as expected, isopycnals shoaling toward higher latitudes and eventually outcropping with the surface near the Antarctic continent. We note that although this isopycnal is well represented in our dataset (see Fig. 2b), it is deeper than $2000 \mathrm{~m}$ over much of region north of the ACC. Figure $3 \mathrm{~b}$ shows IPV on the same isopycnal, which increases poleward, as expected. However, it is worth noting that the IPV structure is not zonally homogeneous, and there are regions of stronger and weaker meridional gradients, which, according to Eq. (9), can indicate regions of enhanced eddy volume transport. Finally, Fig. $3 c$ shows the geostrophic current speed computed from the gradient of the absolute geostrophic streamfunction. The currents appear realistic: they form jets and show steering by topography. The strength of these mean currents is important for the suppression of eddy volume fluxes, as will become apparent in sections 4 and 5 .

As the following analysis of the overturning is conducted in streamwise coordinates, we also require a definition of the coordinate system. Here, we follow Viebahn and Eden (2012) and assume that the depthvarying streamfunctions that ensure that the time-mean geostrophic transport vanishes can be approximated by a single middepth geostrophic contour. Here, we choose the geostrophic streamfunction $M$ on the $27.7 \mathrm{~kg} \mathrm{~m}^{-3}$ neutral density surface as our reference. The 
(a) Depth of $\gamma=27.9 \mathrm{~kg} \cdot \mathrm{m}^{-3}$
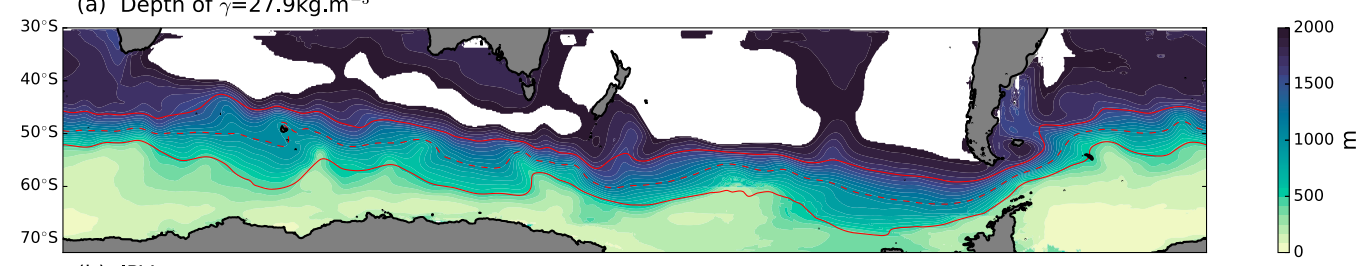

(b) IPV
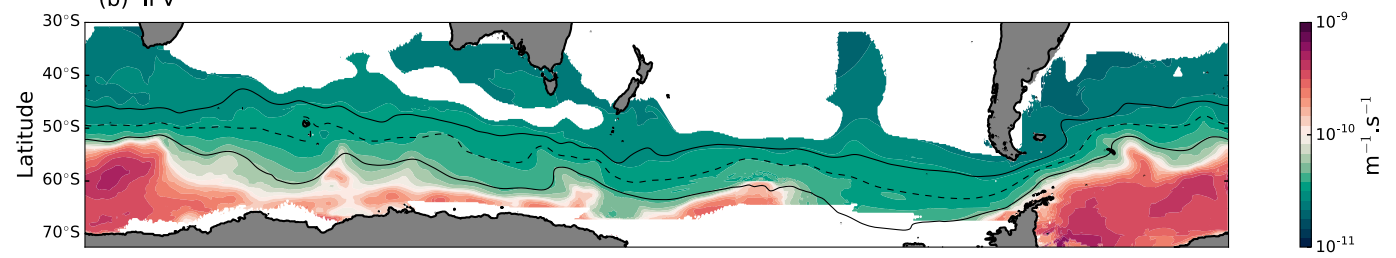

(c) Speed

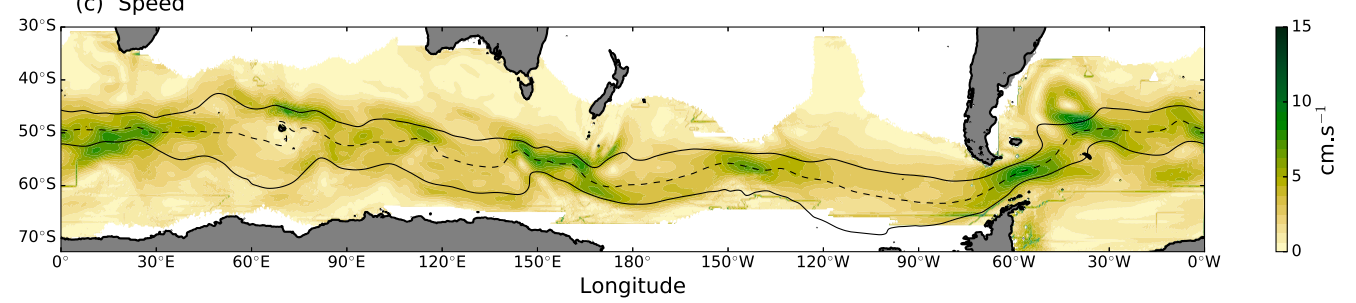

FIG. 3. The climatology of the Southern Ocean, determined from combined hydrographic/satellite dataset, on the $\gamma=27.9 \mathrm{~kg} \mathrm{~m}^{-3}$ isopycnal. The (a) depth of the isopycnal, (b) IPV, and (c) zonal current speed. Solid lines indicate the positions of the northern and southern streamlines that bound the ACC, while the dashed line indicates the streamline that corresponds to the central axis of the ACC. Blanked out areas indicate regions with fewer than 200 data points in the interpolation process or where the isopycnal is deeper than $2000 \mathrm{~m}$. Note the logarithmic color scale used for the IPV in Fig. 3b.

ACC region is taken to lie between -10 and $-4.5 \mathrm{~m}$ on this contour. The bounding contours, as well as the ACC's principle axis, are shown as thick, solid, and dashed lines in Fig. 3 and does not deviate appreciably from streamwise coordinate definitions found in the literature (e.g., Karsten and Marshall 2002; Treguier et al. 2007). The chosen geostrophic streamfunction has been smoothed using a 2D Gaussian window filter with a standard deviation of $0.5^{\circ}$ in both directions. Smoothing the streamfunction reduces the problem of having multiple streamfunction values at a particular longitude.

We have tested different definitions of streamwise coordinates, such as the barotropic streamfunction, streamfunctions on other depths, and density contours, and found that our results are quite insensitive to the choice of streamfunction. All vector quantities treated here are resolved into along- and across-streamline components prior to projection onto the streamwise coordinates. All values, both scalar and vector, are then projected onto streamwise coordinates using bilinear interpolation.

\section{The three-dimensional eddy diffusivity}

In this section, we use our climatology to determine a three-dimensional estimate of both the suppressed $K_{\perp}$ and unsuppressed $K_{0}$ eddy diffusivity, following the theoretical framework described by Ferrari and Nikurashin (2010), described in section 2. Recall Eq. (12), in which the total eddy diffusion is written as an unsuppressed diffusivity $K_{0}$ multiplied by a suppression factor that describes the influence of the mean flow on the eddy stirring.

To compute the unsuppressed diffusivity, we use the expression introduced by Holloway (1986) and Keffer and Holloway (1988) that relates the root-mean-square of the streamfunction fluctuations to $K_{0}$ :

$$
K_{0}=\frac{\Gamma}{f}\left(\overline{M^{\prime} M^{\prime}}\right)^{1 / 2},
$$

where $\Gamma$ is a constant mixing efficiency, usually taken to be 0.35 (Klocker and Abernathey 2014). We compute the RMS of the geostrophic streamfunction by first computing the streamfunction fluctuations by subtracting the mean geostrophic streamfunction $\bar{M}$ from each of the instantaneous profiles of $M$. The square of $M^{\prime}$ is then computed for each profile and mapped using the CARS-LOWESS software on a regular longitude/ latitude grid (see Fig. 4a). A highly zonally asymmetric field is produced, with elevated streamfunction variance 
(a) $\overline{M^{\prime} M^{\prime}}$
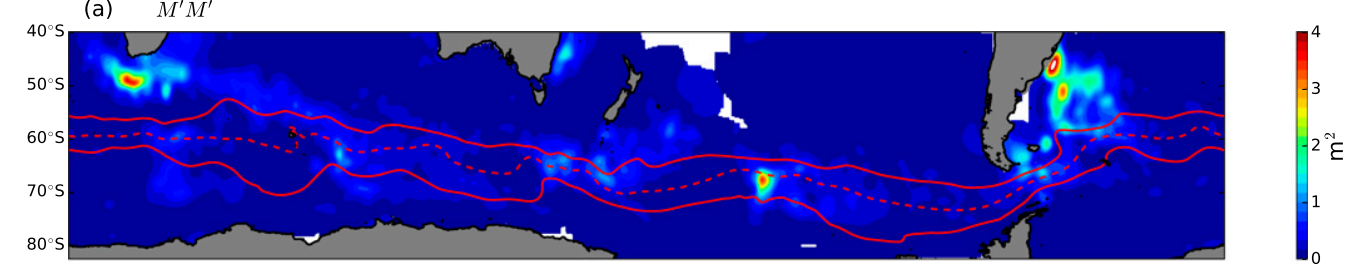

(b) Suppression

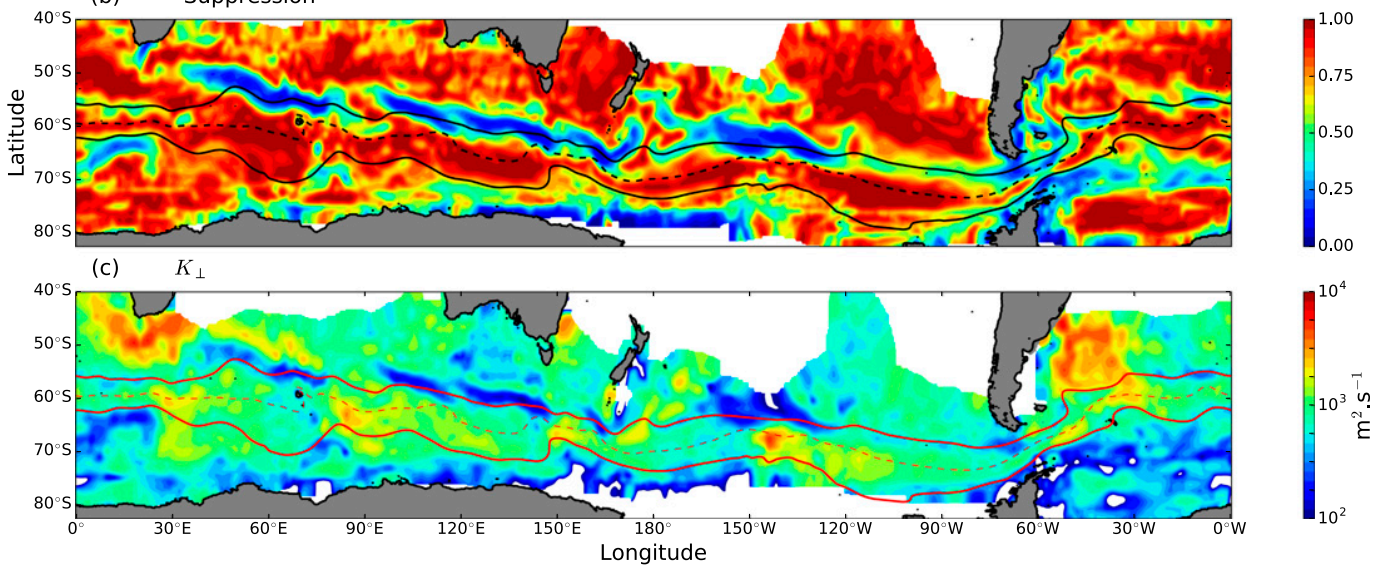

FIG. 4. The across-stream isopycnal diffusivity in the Southern Ocean on isopycnal $\gamma=27.9 \mathrm{~kg} \mathrm{~m}^{-3}$ : the (a) variance of the isopycnal geostrophic streamfunction $\overline{M^{\prime} M^{\prime}}$, (b) diffusivity suppression factor $1 /\left[1+k_{\text {eddy }}^{2} \tau_{\text {eddy }}^{2}\left(c_{p}-\bar{u}\right)^{2}\right]$, and (c) suppressed eddy diffusivity $K_{\perp}$. Solid lines indicate the positions of the northern and southern streamlines that bound the ACC, while the dashed line indicates the streamline that corresponds to the central axis of the ACC. Note the logarithmic color scale in (c).

found in regions downstream of large bathymetric features, in western boundary currents, in the Agulhas region $\left(\sim 20^{\circ}-60^{\circ} \mathrm{E}\right)$, and at the central Pacific Fracture Zone $\left(\sim 140^{\circ} \mathrm{W}\right)$, consistent with previous studies (Sallée et al. 2008; Klocker and Abernathey 2014; Roach et al. 2016).

To compute the suppression factor in the cross-stream direction, we again follow Klocker and Abernathey (2014) and compute the required estimate of the timemean current velocity $\bar{u}$, the eddy phase velocity $\mathbf{c}_{p}$, the eddy decorrelation time scale $\tau_{\text {eddy }}$, and the eddy wavenumber $k_{\text {eddy }}$. The time-mean current velocity $\bar{u}$ is obtained from the gradient of the absolute geostrophic streamfunction $\bar{M}$, as described in section 3d. The eddy phase velocity $\mathbf{c}_{p}$ is calculated using the Rossby wave dispersion relationship, Doppler shifted by the depth mean flow, as suggested by Klocker and Marshall (2014):

$$
\mathbf{c}_{p}=\left(\bar{u}^{z t}-\beta L_{D}^{2}, \bar{v}^{z t}\right),
$$

where $\beta=2\left(\Omega_{E} / R_{E}\right) \cos \phi$ is the meridional gradient of the Coriolis parameter (where $R_{E}=6380 \mathrm{~km}$ is the radius of Earth), $\bar{u}^{z t}$ is the depth-averaged zonal velocity, and $L_{D}$ is the first baroclinic deformation radius. The meridional component of the phase velocity is calculated following Klocker and Abernathey (2014), who assumed that the meridional direction phase speeds were dominated by advective Doppler shift. To compute $L_{D}$, we solve the Sturm-Liouville problem for the neutral modes of the linearized quasigeostrophic equation using the finite-difference scheme of Smith (2007) and our gridded interpolated neutral density. The maps of $L_{D}$ (not shown) produced by this calculation are very similar to those of Chelton et al. (1998), although due to the more complete data coverage provided by the Argo floats, there are fewer regions with missing data, and we find a larger deviation of contours of constant $L_{D}$ near large bathymetric features. The eddy phase velocity is then resolved into the along-streamline direction to give the relevant eddy phase speed.

The eddy decorrelation time scale $\tau_{\text {eddy }}$ is taken to be a constant 4 days, as found by Klocker and Abernathey (2014). Finally, the eddy length scale, used in the calculation of eddy wavenumber $k_{\text {eddy }}=2 \pi / L_{\text {eddy }}$, is estimated by assuming a constant ratio between the eddy size and $L_{D}$, which is approximately valid for strongly nonlinear eddies, such as those found in the Southern Ocean (Klocker and Abernathey 2014). We set this ratio to 2.5 , so that $L_{\text {eddy }}=2.5 L_{D}$.

With all the ingredients assembled, we compute the suppression factor, which is plotted on isopycnal $\gamma=27.9 \mathrm{~kg} \mathrm{~m}^{-3}$ in Fig. 4b. Several regions of heavily suppressed diffusivities (with a suppression factor 
(a)

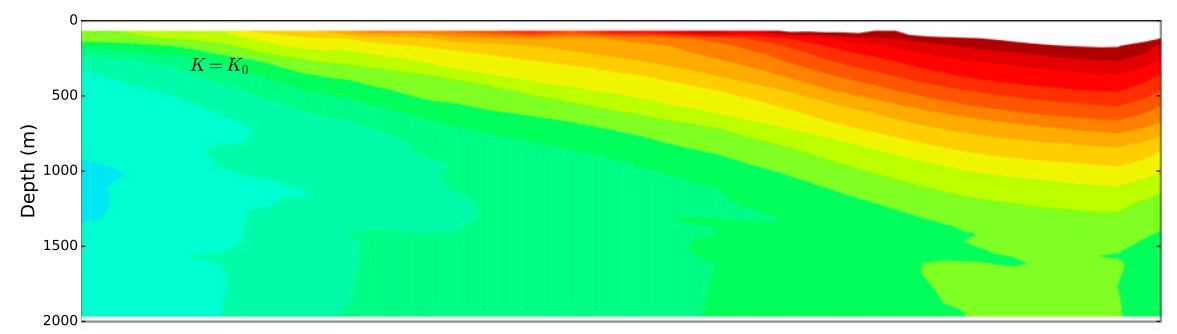

(b)
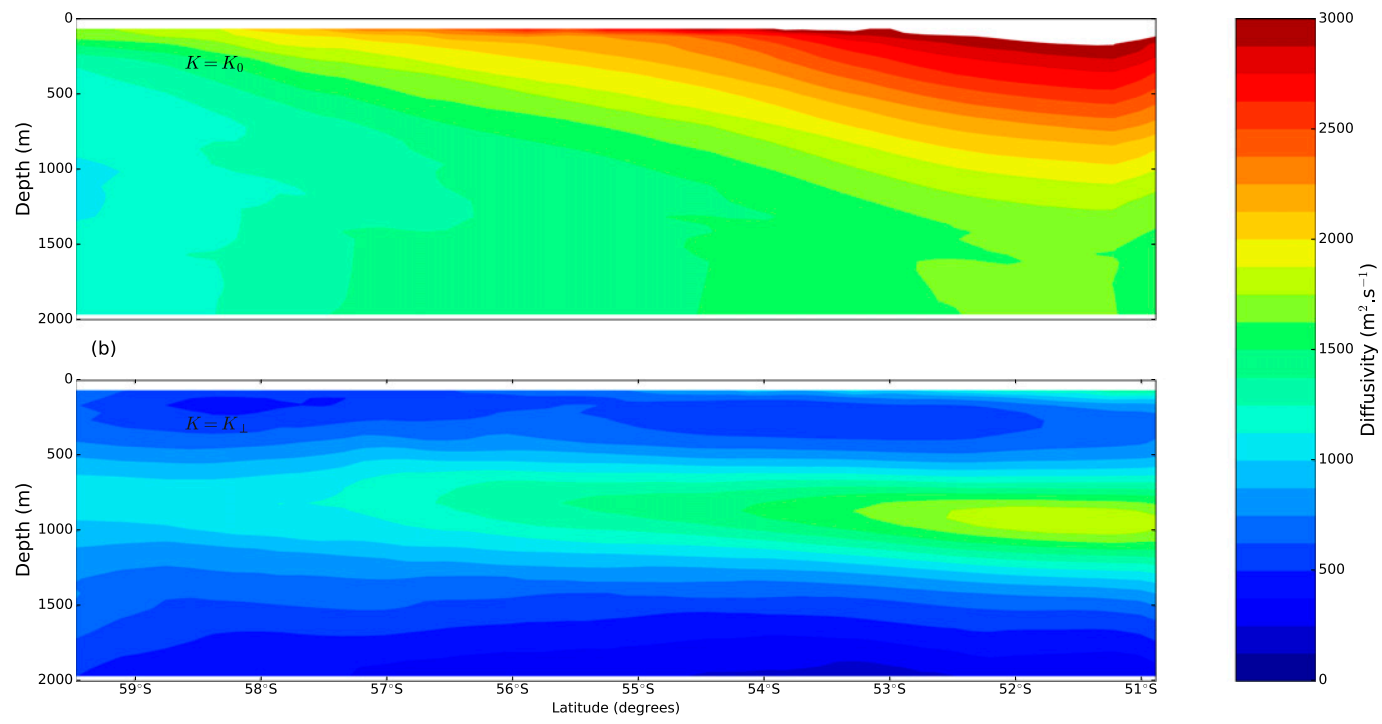

FIG. 5. The across-stream isopycnal diffusivity, projected into streamwise coordinates, zonally averaged (along streamlines) and then mapped to latitude/depth space. (a) The unsuppressed diffusivity $K_{0}$ and (b) the effective diffusivity $K_{\perp}$. The abscissa refers to the average latitude of the streamlines.

between 0 and 0.25 ) are found in regions of strong zonal jets (cf. with Fig. 3c), as expected. The suppression factor computed here shows a strong qualitative resemblance to those computed by Ferrari and Nikurashin (2010) and Klocker and Abernathey (2014) at the surface using altimetry alone. We note that the crossstream diffusivity $K_{\perp}$ is only marginally different to the zonal diffusivity $K_{x}$, due to the dominance of the quasi-zonal ACC flow.

The geographical distribution of the suppressed eddy diffusivity, once again for the isopycnal $\gamma=27.9 \mathrm{~kg} \mathrm{~m}^{-3}$, is plotted in Fig. 4c. Our map appears realistic and shows similar features to the estimate of $K_{\perp}$ by Cole et al. (2015) obtained by considering the decorrelation length scale of salinity fluctuations measured by Argo floats. In particular, we note enhanced regions of $K_{\perp}$ downstream of large topographic features where both streamfunction fluctuations are strong and time-mean flows are weak. When averaged along streamlines and mapped back to depth coordinates, as shown in Fig. 5, we see that the unsuppressed diffusivity $K_{0}$ is strong at the surface and decreases with depth (Fig. 5a). In contrast, $K_{\perp}$ is enhanced at depth, reaching a peak at about $1000 \mathrm{~m}$. This peak in $K_{\perp}$ is found very close to the steering level (where $c_{p} \approx \bar{u}$ ) predicted by Smith and Marshall (2009) using linear theory and that observed by Cole et al. (2015), but it is shallower than the steering level found in Abernathey et al.'s (2010) eddy-permitting simulation (found at about $1750 \mathrm{~m}$ ).

To highlight the important role that bottom bathymetry plays in controlling the diffusivity, we plot $K_{0}$ (red) and $K_{\perp}$ (black) on the isopycnal $\gamma=27.9 \mathrm{~kg} \mathrm{~m}^{-3}$ in Fig. 6a, but now meridionally averaged from the southern boundary of the ACC to the northern boundary of the ACC (determined by finding contours of MDT that correspond to the Southern ACC Front and the Subantarctic Front, as in Sokolov and Rintoul (2007; plotted as solid lines in Fig. 4). The zonal mean of the $K_{0}$ and $K_{\perp}$ (dashed lines in Fig. 6) shows that the suppressing effect of the mean flow acts to reduce the diffusivity by about $500 \mathrm{~m}^{2} \mathrm{~s}^{-1}$ in the ACC latitudes. However, the suppressed diffusivity still peaks downstream of large bathymetric features, reaching its maximum values downstream of the Pacific Antarctic Rise $\left(\sim 140^{\circ} \mathrm{W}\right)$ and downstream of Drake Passage $\left(\sim 60^{\circ} \mathrm{W}\right.$; Fig. 6). The suppressing effect of the mean flow is perhaps most clearly seen at the southeastern Indian Ridge and the Campbell Plateau $\left(\sim 150^{\circ}-170^{\circ} \mathrm{E}\right)$, where $K_{0}$ peaks at about $2500 \mathrm{~m}^{2} \mathrm{~s}^{-1}$, but the suppressed diffusivity does not rise above $1500 \mathrm{~m}^{2} \mathrm{~s}^{-1}$ : a local effective suppression of about $1000 \mathrm{~m}^{2} \mathrm{~s}^{-1}$. The spatial structure of our estimate is similar to that of Roach et al. (2016), shown in Fig. 6b, who used the dispersion of Argo floats at $1000 \mathrm{~m}$ to directly estimate crossstream diffusivity. Roach et al.'s (2016) estimate shows peaks in similar locations to ours, with similar magnitudes, although our estimates of $K_{\perp}$ are substantially lower than theirs at the Campbell Plateau once the suppression factor is applied. The differences between our estimates may arise due to the different formulation used in the estimate, but more likely because the 


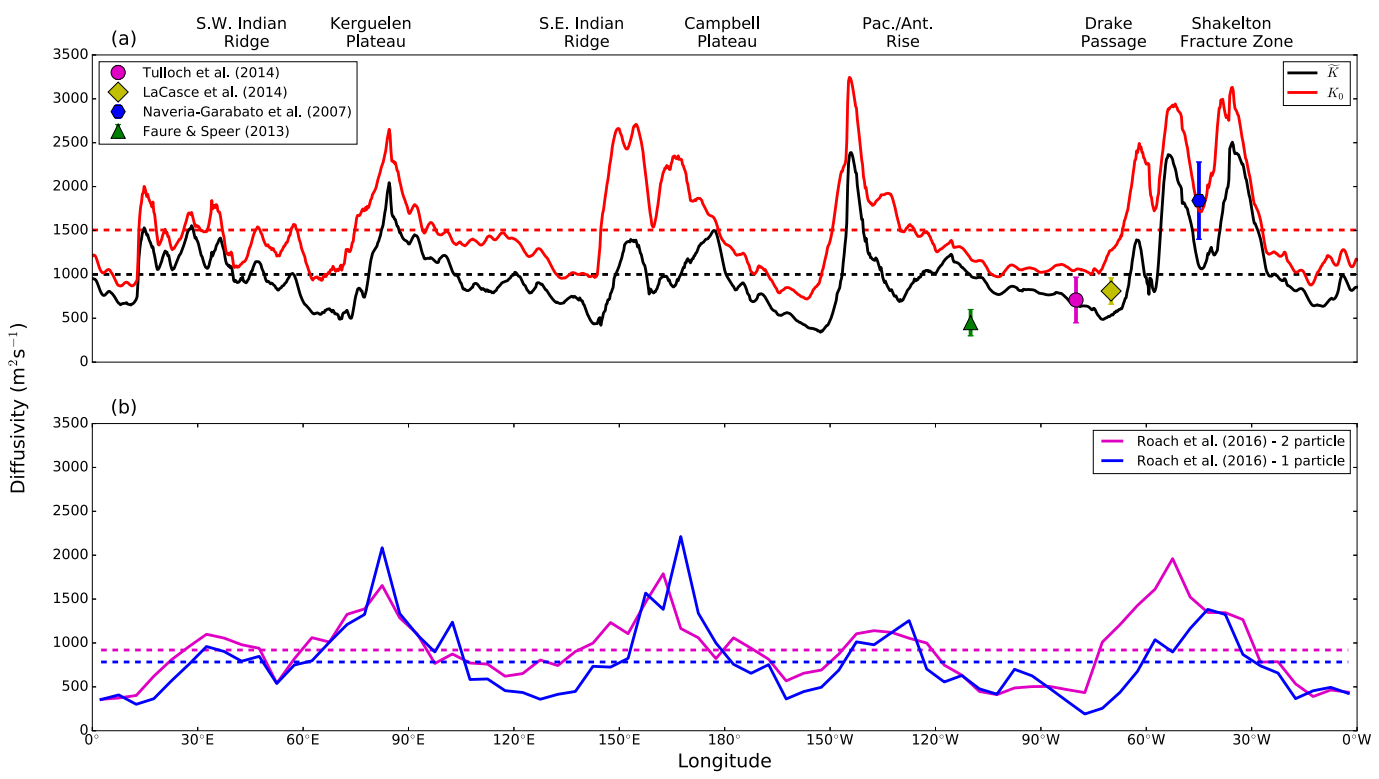

FIG. 6. Variation of diffusivity with longitude. (a) The unsuppressed diffusivity $K_{0}$ (red) and the suppressed diffusivity $K_{\perp}$ (black) averaged over the ACC envelope (solid lines) and their zonal average (dashed lines) on isopycnal $\gamma=27.9 \mathrm{~kg} \mathrm{~m}^{-3}$. For comparison, the estimates of the diffusivity from previous studies are shown as solid markers, and (b) the one and two particle estimates of the diffusivity from Roach et al. (2016) at 1000-m depth are included.

Roach et al. (2016) estimate was made at $1000 \mathrm{~m}$, whereas the isopycnal $\gamma=27.9 \mathrm{~kg} \mathrm{~m}^{-3}$ is closer to $1500 \mathrm{~m}$ in the ACC (see Fig. 3a).

We compare our estimated diffusivities with several estimates made near Drake Passage by direct measurement (Naveira Garabato et al. 2007; Faure and Speer 2012; LaCasce et al. 2014; Tulloch et al. 2014). We find that our estimate of the effective diffusivity agrees broadly with these other estimates, although we note that our estimates are significantly higher than those of Faure and Speer (2012) and somewhat lower than those of Naveira Garabato et al. (2007). However, given the difficulty in estimating certain parameters in the suppression factor, the reasonably close agreement between our estimate of $K_{\perp}$ and previous local or regional estimates gives us some confidence in our maps of eddy diffusivity.

\section{Reconstruction of the MOC}

As described in section 2, the MOC can be decomposed into a time-mean Ekman component $\bar{h} v_{\text {Ekman }}$, a time-mean geostrophic component $\bar{h} v_{g}$, and the transient eddy component $\overline{h^{\prime} v_{g}^{\prime}}$. In this section, we compute each of these components from observations in order to reconstruct the residual overturning streamfunction and describe how it is influenced by the spatial variation and suppression of the diffusivity.

\section{a. Eulerian-mean overturning}

The components of the time-mean overturning are determined by computing the Ekman ageostrophic velocity from Eqs. (6) and (7) and by computing the time-mean geostrophic velocity $\mathbf{u}_{g}$ from the absolute geostrophic streamfunction $M$ and Eq. (8). We then determine a time-mean isopycnal layer thickness $\bar{h}$ by simply taking the difference in the depths of the isopycnal layer interfaces:

$$
\bar{h}_{j}=z_{j+1 / 2}-z_{j-1 / 2},
$$

where $j$ is the index of the $j$ th isopycnal layer. The results are projected into streamwise coordinates and integrated zonally and vertically to give the mean overturning streamfunctions $\bar{\Psi}_{\text {Ekman }}$ and $\bar{\Psi}_{g}$ and the total mean overturning $\bar{\Psi}=\bar{\Psi}_{\text {Ekman }}+\bar{\Psi}_{g}$. These streamfunctions are plotted in Fig. 7.

The zonally integrated Ekman-driven overturning $\bar{\Psi}_{\text {Ekman }}$, shown in Fig. 7a, consists of a single clockwise overturning cell that transports around $20 \mathrm{~Sv}$ of water northward at the surface and drives a strong upwelling at approximately $60^{\circ} \mathrm{S}$. Our Ekman overturning streamfunction is similar in structure and magnitude to those obtained from numerical simulation forced by similar atmospheric reanalysis (Treguier et al. 2007; Dufour et al. 2012; Mazloff et al. 2013). The cross-stream geostrophic streamfunction, by virtue of having been 

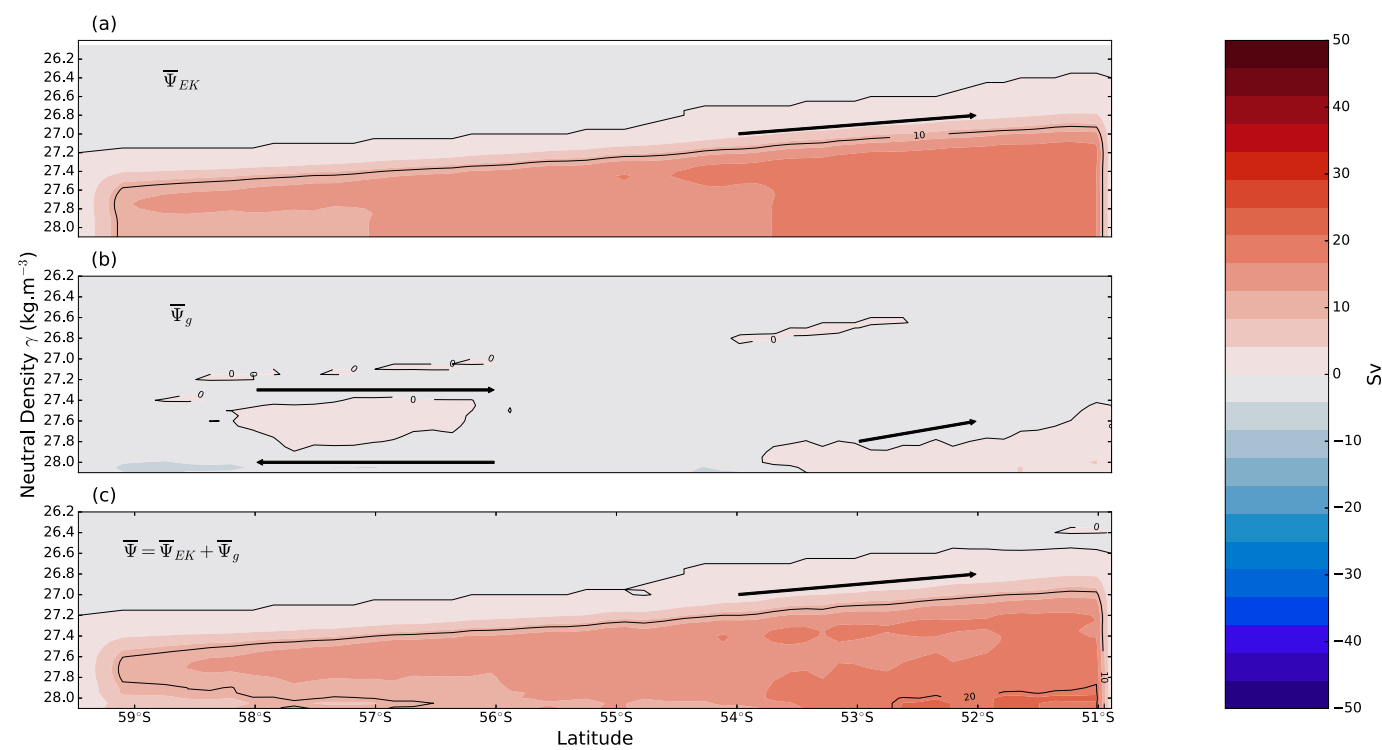

FIG. 7. The time-mean overturning streamfunction: (a) the Ekman overturning $\bar{\Psi}_{\text {Ekman }}$, (b) the geostrophic overturning $\bar{\Psi}_{g}$, and (c) the total time-mean overturning $\bar{\Psi}=\bar{\Psi}_{\text {Ekman }}+\bar{\Psi}_{g}$. Positive (negative) values indicate clockwise (counterclockwise) transport, as indicated by the arrows.

computed in streamwise coordinates, is small but nonzero, as the mean flow in the ACC is not perfectly equivalent barotropic and we have employed a streamfunction on a single middepth layer to define our coordinate system. The mean geostrophic streamfunction contributes a maximum of about $4 \mathrm{~Sv}$ of transport with no strongly coherent spatial structure.

The total mean overturning $\bar{\Psi}$ (Fig. 7c) is little changed from the ageostrophic Ekman-induced overturning. A peak transport of approximately $20 \mathrm{~Sv}$ is found near the northern boundary of the ACC (at approximately $50^{\circ} \mathrm{S}$ ) on the $28.0 \mathrm{~kg} \mathrm{~m}^{-3}$ isopycnal surface. Once again, our estimate of the mean overturning is consistent with previous estimates (e.g., Treguier et al. 2007, see their Fig. 9). The total mean overturning is clockwise, with lighter surface waters moving northward and upwelling of denser waters occurring near the southern ACC boundary at around $60^{\circ} \mathrm{S}$.

\section{b. Eddy overturning}

We now discuss the contributions of transient geostrophic eddies to the MOC. Here, we employ the simple downgradient diffusive closure given by Eq. (11). To understand the influence of the suppression of the eddy diffusivity by the mean flow on the overturning, we reconstruct the eddy volume flux using both the unsuppressed diffusivity $K_{0}$ and the suppressed diffusivity $K_{\perp}$.

The longitudinal/vertical structure of meridional IPV gradient and its relationship with the parameterized eddy fluxes is plotted in Fig. 8, which shows the cross- stream IPV gradient (Fig. 8a) and estimates of the eddy volume flux using both suppressed and unsuppressed diffusivities (Figs. 8b,c), averaged over the ACC envelope. Despite the argument that IPV should be relatively homogenized in the ocean interior (Marshall et al. 1993), we find substantial IPV gradients in certain regions, particularly downstream of large bathymetric features, a fact that has been remarked upon by previous authors (Thompson and Naveira Garabato 2014). As a result, both the unsuppressed and suppressed eddy fluxes (Figs. 8b,c) are concentrated in regions downstream of topography, which is also consistent with previous work (Thompson and Sallée 2012; Dufour et al. 2015). Additionally, we note that there is a change in the sign of the IPV gradient in the lighter, surface waters, leading to a northward volume transport near the surface in certain regions. The northward transport in the surface waters is in contrast to the general southward eddy transport in the interior. The northward eddy flux of light waters, consistent with the reversal of sign of the IPV gradients in the near-surface layers, was discussed in depth by Mazloff (2008).

The suppression of the eddy flux by the mean flow can be seen by comparing the transports computed with the unsuppressed (Fig. 8b) and suppressed (Fig. 8c) diffusivities. As expected, the cross-stream eddy volume transports are much larger when the unsuppressed diffusivity is used in the reconstruction. When mean flow suppression is taken into account, the majority of the near-surface transport disappears. Additionally, the 


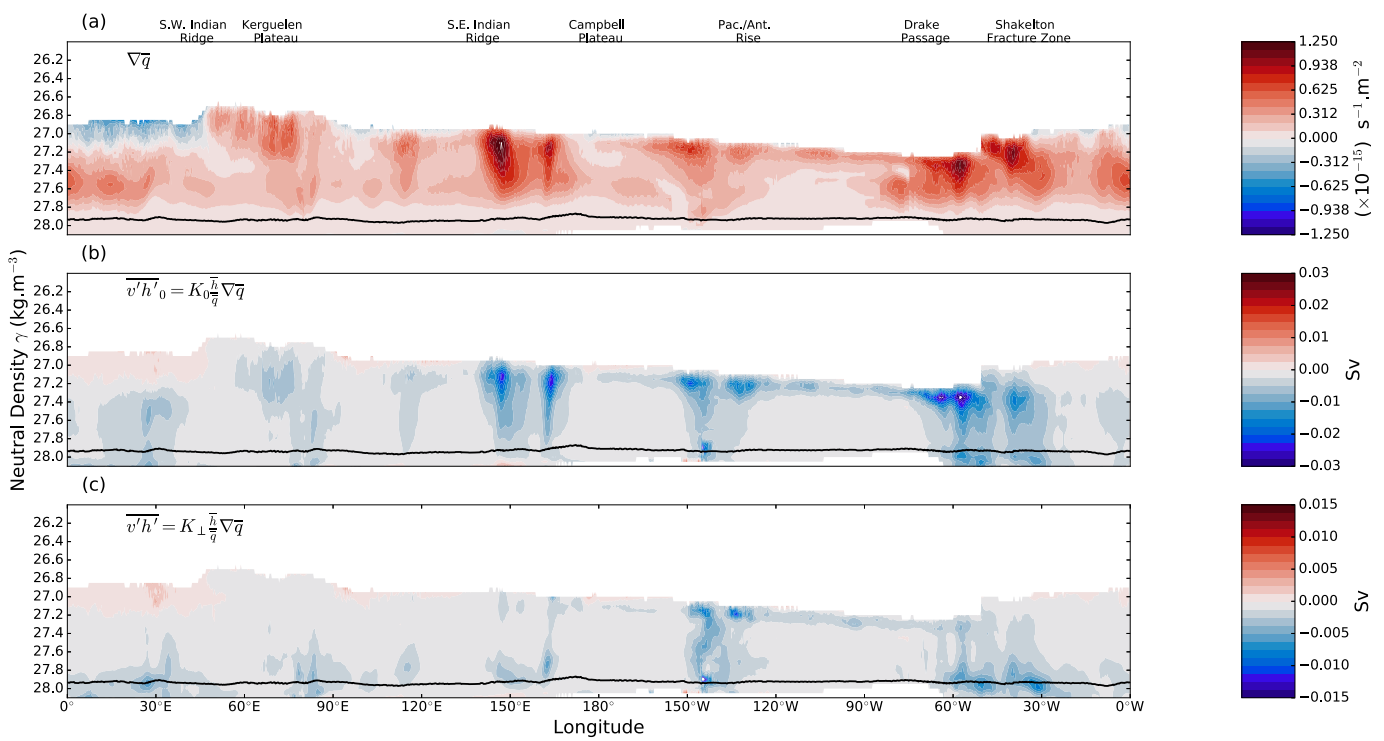

FIG. 8. The relationship between the meridional IPV gradient and the parameterized eddy flux averaged over the ACC latitude envelope: (a) the meridional IPV gradient; (b) the derived geostrophic eddy volume flux $\overline{h^{\prime} v^{\prime}}$, computed from Eq. (11) using the unsuppressed eddy diffusivity $K_{0}$; and (c) as in (b), but using the effective eddy diffusivity $K_{\perp}$. Solid black lines denote the average 1000-m depth contour, the approximate critical layer depth. Note the differing color scales between the unsuppressed in (b) and suppressed in (c) transport.

vertical structure of the transport varies between the suppressed and unsuppressed cases. The unsuppressed transport shows a vaguely common horizontal structure on most isopycnal surfaces, while the suppressed eddy transport shows minimal interior transports away from the Pacific-Antarctic Rise (between $150^{\circ}$ and $130^{\circ} \mathrm{W}$ ) and Drake Passage (between $40^{\circ}$ and $30^{\circ} \mathrm{W}$ ). While the unsuppressed transport is typically strongest near the surface, the interior suppressed transport is intensified near the critical layer (at approximately 1000-m depth, indicated by the solid black line in Fig. 7).

In Fig. 9, we plot the parameterized zonally integrated eddy overturning streamfunction computed using the unsuppressed (Fig. 9a) and the suppressed (Fig. 9b) diffusivities as well as the difference between them (Fig. 9c). We note that although the parameterization used here is extremely crude, we are able to capture a surprisingly large degree of the eddy overturning streamfunction computed using eddy-permitting numerical models (Treguier et al. 2007; Dufour et al. 2012; Mazloff et al. 2013; Zika et al. 2013). In particular, the overturning streamfunction is generally counterclockwise in a streamline density plane for both suppressed and unsuppressed diffusivities. We note a weak, northward flow in the light, near-surface waters that generally reinforce the Ekman currents, below which is a stronger, generally southward flow that opposes the mean overturning. In contrast to the Southern Ocean State Estimate (SOSE) output, our calculations show a general increase in the strength of the eddy overturning streamfunction with depth. We find southward overturning transports of around $10 \mathrm{~Sv}$ at $\gamma=27.8 \mathrm{~kg} \mathrm{~m}^{-3}$ at $55^{\circ} \mathrm{S}$ when computed with suppressed diffusivities. The suppressed and unsuppressed transports are different by about a factor of 2 at $55^{\circ} \mathrm{S}, 27.8 \mathrm{~kg} \mathrm{~m}^{-3}$. This factor increases to $\sim 2.5$ with increasing density and latitude: at $28.0 \mathrm{~kg} \mathrm{~m}^{-3}, 51^{\circ} \mathrm{S}$, the unsuppressed transport is $\sim 45 \mathrm{~Sv}$, while the suppressed transport is $\sim 20 \mathrm{~Sv}$

To further investigate the influence of the threedimensional diffusivity on the MOC, we compare the zonally integrated eddy volume transport $\overline{v^{\prime} h^{\prime}}$ (i.e., the transport itself, not the streamfunction) computed using our diffusivity estimates to the transport obtained assuming constant diffusivities of between 500 and $3500 \mathrm{~m}^{2} \mathrm{~s}^{-1}$, meridionally averaged over the ACC envelope (Fig. 10a). A similar zonal and meridional averaging is applied to the spatially variable diffusivities $K_{0}$ and $K_{\perp}$ (Fig. 10b). It is clear from Fig. 10a that the vertical structure of the meridional transport obtained using $K_{0}$ resembles those obtained using constant diffusivities, with relatively strong southward transports in the ocean interior that peak at $\gamma=27.3 \mathrm{~kg} \mathrm{~m}^{-3}$ that decreases slowly with increasing density.

In contrast, the interior southward transport determined using the suppressed eddy diffusivity is much more modest and has a different vertical structure, reaching a peak near the critical layer, which occurs at approximately $27.8 \mathrm{~kg} \mathrm{~m}^{-3}$. At this critical level, the 

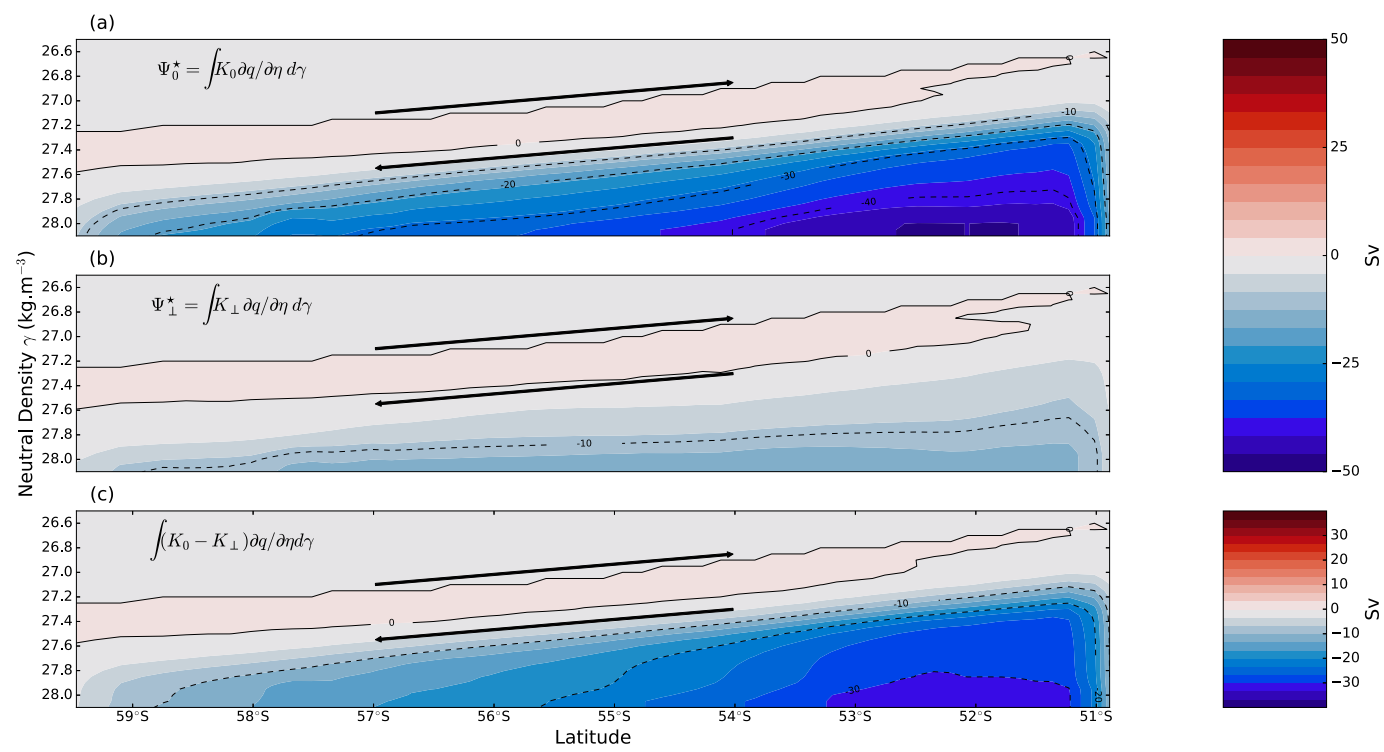

FIG. 9. The geostrophic eddy overturning streamfunction computed from Eq. (9). (a) $\Psi^{\star}$ computed using the unsuppressed diffusivity $K_{0}$, (b) $\Psi^{\star}$ computed using the suppressed diffusivity $K_{\perp}$, and (c) the difference between the eddy overturning streamfunctions computed using $K_{0}$ and $K_{\perp}$. Positive (negative) streamfunction values denote clockwise (counterclockwise) flow, as indicated by the black arrows. Note the different color scale used for (c).

difference between the suppressed and unsuppressed transport is less than $1 \mathrm{~Sv}$. Higher in the water column, the difference between suppressed and unsuppressed transports is as much as $4 \mathrm{~Sv}$. In short, the mean flow of

(a)

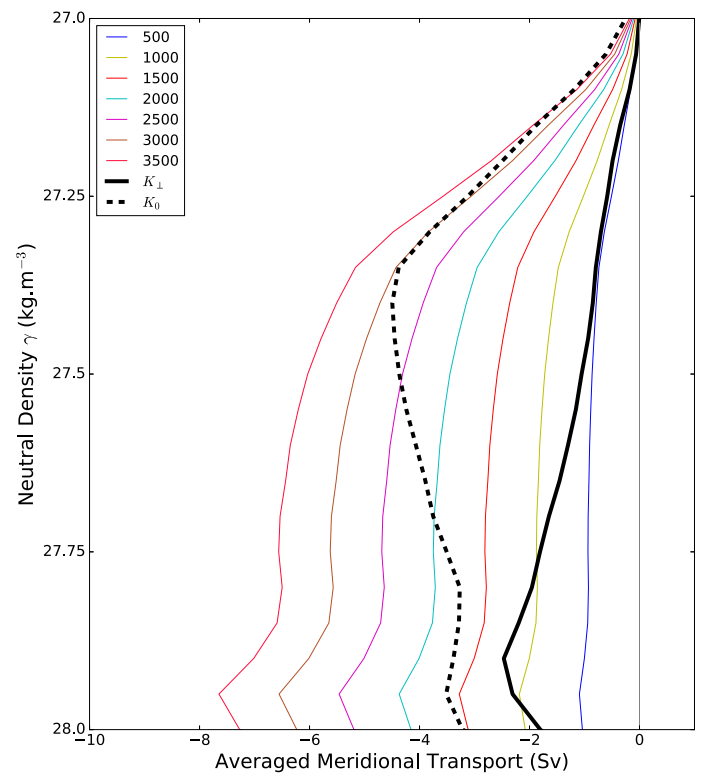

the ACC strongly suppresses the intensity of eddy diffusion, which dramatically reduces the southward interior geostrophic eddy-induced transport and concentrates it in the denser water masses near the critical

FIG. 10. The meridional geostrophic eddy transport $\overline{v^{\prime} h^{\prime}}=K(\bar{h} / \bar{q})(\partial \bar{q} / \partial y)$, using variable and constant diffusivities. (a) The meridional transport, zonally integrated and averaged over the ACC latitudes, obtained from Eq. (11) using the suppressed and unsuppressed spatially variable diffusivity (thick black lines, $K=K_{0}$ dashed, $K=K_{\perp}$ solid) and using a constant diffusivity (thin colored lines) between 500 and $3500 \mathrm{~m}^{2} \mathrm{~s}^{-1}$. Southward transports are negative, northward positive, and zero transport is indicated by the thin gray line. (b) The suppressed (solid) and unsuppressed (dashed) diffusivities, zonally averaged over the entire Southern Ocean, and meridionally averaged in the ACC latitudes. 
layer. Assuming that the simple parameterization used here is valid, it is clear that the modification of the vertical structure of the diffusivity has important implication for the Southern Ocean overturning.

Comparing the transport calculated using constant diffusivities to those obtained using both suppressed and unsuppressed diffusivities allows further understanding of the influence of diffusivity suppression on the eddy flux. It is notable that no value of constant diffusivity accurately captures the vertical structure of the transport calculated using $K_{0}$ or $K_{\perp}$ in waters denser than $\sim 27.3 \mathrm{~kg} \mathrm{~m}^{-3}$. In waters lighter than this value, the transport obtained using the unsuppressed diffusivity is well approximated by a constant diffusivity of $3000 \mathrm{~m}^{2} \mathrm{~s}^{-1}$, and the transport obtained using the suppressed diffusivity is well approximated by a constant value of $500 \mathrm{~m}^{2} \mathrm{~s}^{-1}$. Below $27.3 \mathrm{~kg} \mathrm{~m}^{-3}$, no value of constant diffusivity can approximate the estimated vertical transport structure. However, the transport averaged below $\gamma=27.3 \mathrm{~kg} \mathrm{~m}^{-3}$ can be approximated with a constant diffusivity of $2200 \mathrm{~m}^{2} \mathrm{~s}^{-1}$ in the case of unsuppressed diffusivity and a value of $750 \mathrm{~m}^{2} \mathrm{~s}^{-1}$ for the case with suppressed diffusivities. As such, the effects of the suppression of the diffusivity due to the time-mean flow can be compared, in an ocean with constant diffusivity, to a reduction of that diffusivity by $65 \%-85 \%$.

\section{c. The residual overturning}

With the time-mean and eddy components of the overturning in hand, we are now able to reconstruct the total residual meridional circulation [Eq. (4)] and its overturning streamfunction [Eq. (5)]. The zonally integrated residual overturning streamfunction $\Psi^{\text {res }}$ is shown using the unsuppressed diffusivities in Fig. 11a, using the suppressed diffusivities in Fig. $11 \mathrm{~b}$ and the difference between them in Fig. 11c.

First, we note that our estimated residual overturning streamfunctions show numerous features in common with those computed from sophisticated numerical models (Treguier et al. 2007). For both the suppressed and unsuppressed diffusivities, a clear positive (i.e., clockwise) overturning cell forms in the $\gamma=26.8$ $27.8 \mathrm{~kg} \mathrm{~m}^{-3}$ density range, corresponding to the Upper Circumpolar Deep Water (UCDW) and Antarctic Intermediate Water (AAIW) classes. These clockwise overturning cells have peak transports in the order of $15-20 \mathrm{~Sv}$, which is of a similar order of magnitude to that found in numerical models.

There are distinct differences between the overturning structures formed using the suppressed and unsuppressed diffusivities. In particular, the unsuppressed overturning streamfunction $\Psi_{K_{0}}^{\text {res }}$ shows a two-cell structure, with a strong counterclockwise overturning cell found in deeper waters and strong diabatic downwelling (i.e., downwelling across isopycnal surfaces). In contrast, only a single dominant overturning cell is present in the suppressed overturning streamfunction $\Psi_{K}^{\text {res }}$. This clockwise cell closes at $\gamma=28.0 \mathrm{~kg} \mathrm{~m}^{-3}$. At this depth, water moves adiabatically southward before being upwelled near the southern boundary of the ACC, where it returns northward. There is the hint of a weak counterclockwise cell, consistent with the deep abyssal cell, although our dataset does not sufficiently sample waters denser than $28 \mathrm{~kg} \mathrm{~m}^{-3}$ to completely resolve the northward abyssal cell.

In comparing $\Psi_{K_{\perp}}^{\mathrm{res}}$ and $\Psi_{K_{0}}^{\mathrm{res}}$ with previous studies using numerical models it is clear that $\Psi_{K_{\perp}}^{\text {res }}$ more closely resembles the canonical structure of the MOC's upper branch. Without taking into account the suppression of the mean flow, the counterclockwise eddy-induced overturning is likely far too strong, which results in an overcompensation of the Eulerian overturning and the shallowing of the clockwise overturning cell (seen most clearly in Fig. 11c). Additionally, the diabatic downwelling present in $\Psi_{K_{0}}^{\text {res }}$ that arises due to the intensity of the inferred eddy flux is likely not a real physical effect. Although, there is also the hint of a similar effect in $\Psi_{K_{\perp}}^{\text {res }}$, which can be seen in tilt of the 10-Sv transport contour in Fig. 11b, it must be noted that this diabatic transport is much reduced when the suppression of diffusivities is taken into account.

As such, although our reconstructions show numerous realistic features, perfect reconstruction eludes us. When comparing our results with the SOSE reconstruction (Mazloff 2008; Mazloff et al. 2013) and other high-resolution models that compute the overturning streamfunctions in streamwise coordinates (e.g., Treguier et al. 2007), we find that when using the suppressed diffusivities that the zero Sverdrup transport line that separates the upper overturning cell from the abyssal cell is too dense. It is likely that the eddy volume flux of the present study estimated using the suppressed diffusivities is too weak in lighter waters and too strong in denser waters, while that estimated using the unsuppressed diffusivities is too strong everywhere except in the near-surface waters. However, the realistic overturning structure produced by the unsuppressed estimate does allow us to conclude that the suppressing effect of the mean flow on the eddy diffusivities has important implications for the cross-stream flux in the Southern Ocean.

We can explore the distribution of the meridional volume transport throughout the Southern Ocean by calculating the vertically integrated cumulative transport, averaged over the ACC envelope, as shown in 


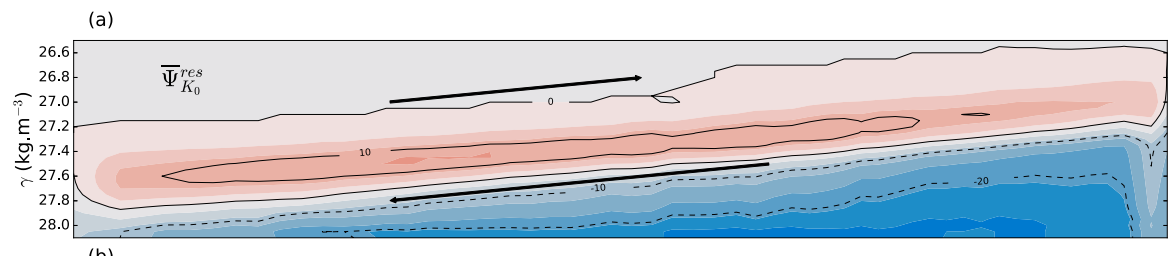

(b)

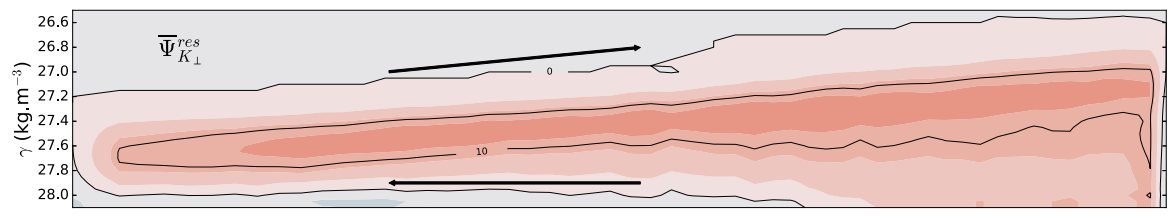

(c)

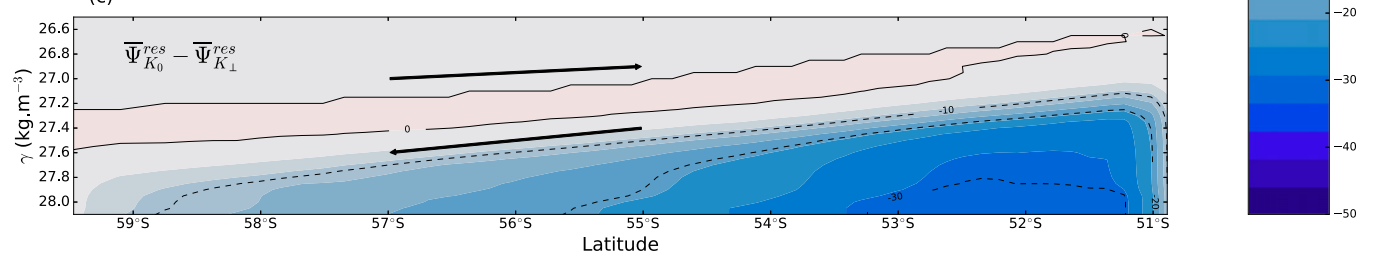

FIG. 11. The residual overturning streamfunction $\Psi^{\text {res }}$ reconstructed from the observations. (a) The residual overturning streamfunction calculated using the unsuppressed diffusivity $K_{0}$. (b) As in (a), but calculated using the suppressed diffusivity $K_{\perp}$. (c) The difference between the $\Psi_{K_{0}}^{\mathrm{res}}$ and $\Psi_{K_{\perp}}^{\mathrm{res}}$. Positive (negative) values indicate clockwise flow. Arrows indicate the sense of the overturning.

Fig. 12. Here, we can gauge the influence of the Southern Ocean's bathymetry on the meridional transport as well as see how the diffusivity suppression influences the transport around the Southern Ocean. We see that, similarly to the cross-frontal transport computed from a high-resolution numerical model by Dufour et al. (2015), both the suppressed and unsuppressed eddy transport are concentrated into a series of step changes of enhanced southward transport near certain bathymetric features, most clearly seen in the unsuppressed transport. These locations correspond to the locations "storm tracks" or "mixing hot spots" identified by previous studies (Thompson and Sallée 2012; Dufour et al. 2015; Chapman et al. 2015). However, these concentrated regions of southward transport are generally limited in magnitude, being between 2 and $5 \mathrm{~Sv}$ for the unsuppressed diffusivities and 5-10 Sv for the suppressed diffusivities. Note that the cross-stream mean geostrophic transport $\bar{v}_{g}$ is included in the total transport calculation but is not shown here due to its small magnitude.

\section{Influence of a vertically varying $K$ in a simple conceptual model}

We have shown that the primary influence of the three-dimensional structure of the eddy diffusivity on the MOC is the reduction of interior eddy volume flux. We posit that without the suppression of the eddy diffusivity due to the mean flow, unrealistically high southward fluxes would be inferred on certain isopycnal layers. We now attempt to further understand the influence that vertically variable diffusivity has on the stratification and the overturning by using a simple conceptual model presented in section 2 [Eqs. (14)-(16)].

In lieu of a constant diffusivity $K$, we employ in Eq. (16) a diffusivity with a simple vertically varying structure:

$$
\tilde{K}(z)=K_{0}+K^{\star} e^{-\left(z-z_{c}\right)^{2} /\left(2 h_{K}^{2}\right)} .
$$

In this form, the diffusivity is enhanced at depth, with a peak amplitude of $K^{\star}$ at the critical level $z_{c}$. The vertically varying part of $K$ is superposed over a constant background diffusivity $K_{0}$. The model is run over a broad parameter space, with critical layers ranging from 750 - to 2000-m depth and peak $K^{\star}$ from 500 to $10 \times 10^{3} \mathrm{~m}^{2} \mathrm{~s}^{-1}$. The background diffusivity $K_{0}$ is set to $250 \mathrm{~m}^{2} \mathrm{~s}^{-1}$, and the vertical scale $h_{k}$ is set to $500 \mathrm{~m}$. Additionally, we run the model with a constant, vertically invariant $K$, ranging from 500 to $3500 \mathrm{~m}^{2} \mathrm{~s}^{-1}$. The large range of $K^{\star}$ has been chosen so that we may effectively compare both the peak diffusivity and the vertically averaged diffusivity ${\overline{K^{\star}}}^{z}=\int_{0}^{H} d z K^{\star} / H$ parameters with the results obtained using a constant diffusivity. Thus, in order to obtain averaged diffusivities of $3500 \mathrm{~m}^{2} \mathrm{~s}^{-1}$, we required a peak diffusivity of $10 \times 10^{3} \mathrm{~m}^{2} \mathrm{~s}^{-1}$ in the variable diffusivity configuration. 


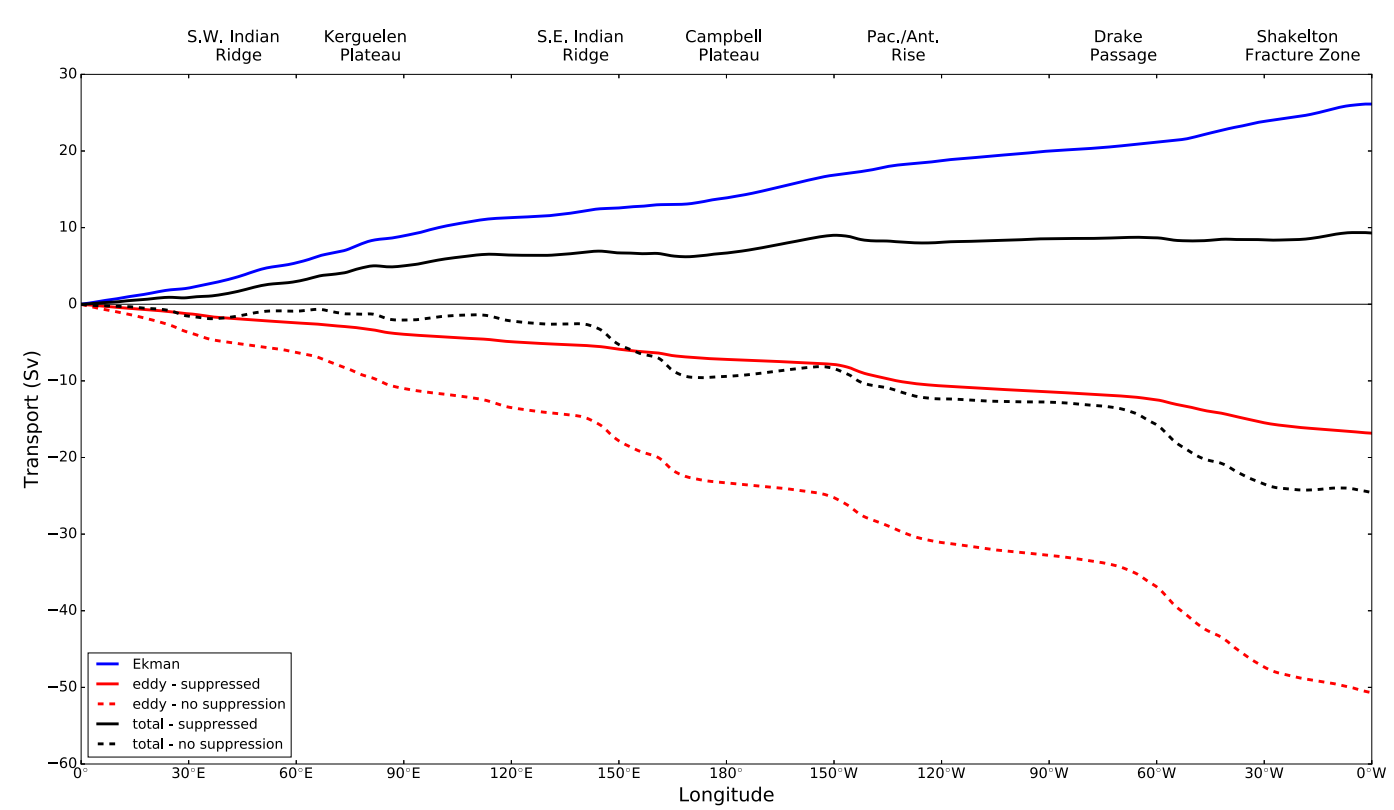

FIG. 12. The longitudinal variation of the vertically integrated cumulative meridional transport and each of its components, averaged over the ACC latitudes. The ageostrophic Ekman transport $\bar{v}_{\text {Ekman }} \bar{h}$ (blue). The geostrophic eddy transport $\overline{v_{g}^{\prime} h^{\prime}} \approx K(\bar{h} / \bar{q}) \nabla \bar{q}$ (red) for the suppressed (solid) and unsuppressed (dashed) diffusivities, and the total transport $\overline{v h}=\bar{v}_{\text {Ekman }} \bar{h}+\bar{h} \bar{v}_{g}+\overline{v_{g}^{\prime} h^{\prime}}$ (black) for the suppressed (solid) and unsuppressed (dashed) diffusivities. Note that the mean geostrophic flux is included in the total transport calculation but is not shown here.

Figure 13 contrasts the results of the TEM model using a constant eddy diffusivity $K=1500 \mathrm{~m}^{2} \mathrm{~s}^{-1}$ and using the vertically varying $K$ with peak amplitude $K^{\star}$ of $1500 \mathrm{~m}^{2} \mathrm{~s}^{-1}$. Both the buoyancy field [Fig. 13 (top)] and the residual overturning streamfunction [Fig. 13 (bottom)] show the same basic structure for the constant diffusivity [Fig. 13 (left)] and the vertically varying diffusivity [Fig. 13 (right)] but with some important differences. Principally, the isopycnal inclination is greater in the case with vertically varying $\tilde{K}$ than with constant $K$. Second, the maximum $\Psi^{\text {res }}$ is about 10 Sv larger in the vertically varying case. Since the time-mean overturning is identical in both cases, we conclude that the opposing eddy overturning is weaker for vertically varying diffusivity, despite the increased isopycnal tilt that should, by Eq. (15), lead to a higher eddy volume fluxes. As such, it seems that the principle result of the suppression of the eddy diffusivity in the ocean interior is to reduce the eddy-induced overturning, which in turn results in a steeper isopycnal slope.

To underline this point further, Fig. 14 shows the influence of varying the critical layer $z_{c}$ and the peak eddy diffusivity $K^{\star}$ on the stratification and the residual overturning and how the results using a vertically varying diffusivity differ from those with a constant diffusivity. Figure 14a shows the depth of a representative isopycnal (in this case $\bar{b}=0.2 \mathrm{~m} \mathrm{~s}^{-2}$, which is found at 1200-m depth on the northern boundary) at approximately $45^{\circ} \mathrm{S}$. It can be seen clearly that this isopycnal shallows with increasing diffusivity and that the shallowing of isopycnals approaches a limit with increasing $K$. It can also been seen in Fig. 14a that as the critical layer depth increases (solid colored curves), the depth of the isopycnal also increases. When $K$ is constant (dashed curve) the isopycnal depth is far more sensitive to changes in the $K$ than at equivalent diffusivities in the vertically varying cases. As the critical layer deepens, the diffusivity "felt" on this isopycnal (whose depth is constrained to be $1200 \mathrm{~m}$ on the northern boundary), at this latitude, increases, resulting in a flattening of the isopycnal. The exact response of the isopycnal depth depends on the choice of isopycnal and where it lies in relation to the critical layer. As such, changes in the $z_{c}$ can modify vertical density gradient in the interior and, hence, the thickness of isopycnal layers.

The residual overturning streamfunction is also sensitive to changes in $z_{c}$ and $K$. Figure $14 \mathrm{~b}$ shows the maximum value of the residual streamfunction at the northern boundary for each model run. Here, we note that in general the overturning streamfunction decreases approximately linearly with increasing $K$ for both the vertically varying $K$ cases and the constant $K$ case. Indeed, weaker eddy diffusivity reduces the efficiency of the eddy transport to counterbalance the mean 
(a)i

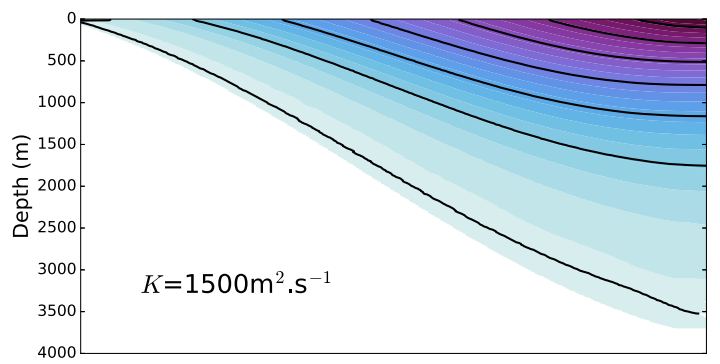

(b)i

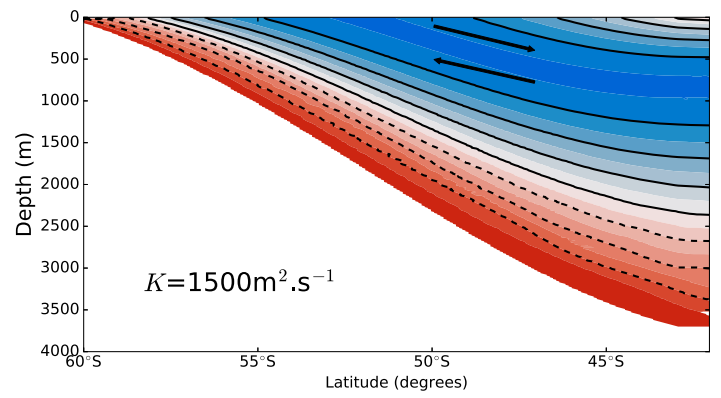

(a) ii

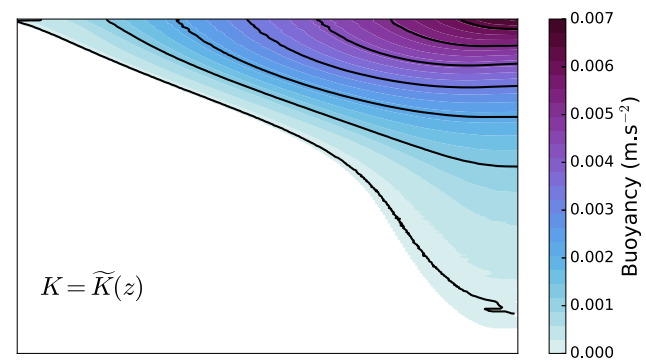

(b)ii

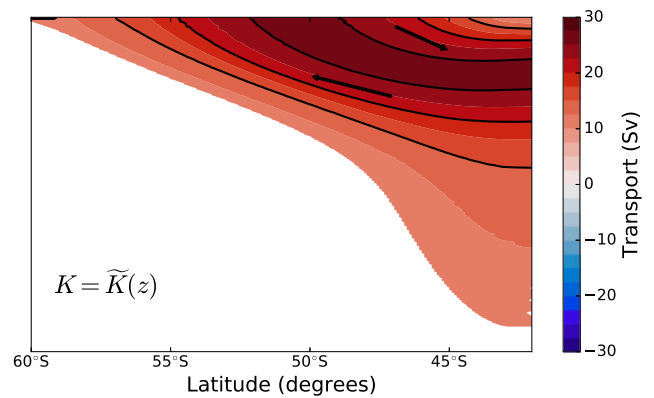

FIG. 13. The effect of a vertically varying diffusivity on the stratification and overturning in a conceptual model. (top) The simulated zonally averaged buoyancy field and (bottom) residual overturning streamfunction $\Psi^{\text {res }}$ from the TEM model for a case with (left) a constant eddy diffusivity $K=1500 \mathrm{~m} \mathrm{~s}^{-2}$ and (right) vertically varying eddy diffusivity, given by Eq. (27) with a maximum diffusivity of $K^{\star}=1500 \mathrm{~m} \mathrm{~s}^{-2}$. Solid black lines indicate contours of buoyancy in (top) [contour interval (CI): $1.0 \times 10^{-3} \mathrm{~m} \mathrm{~s}^{-2}$ ] and overturning streamfunction in (bottom) (CI: $10 \mathrm{~Sv}$ ). The black arrows indicate the sense of the overturning.

transport, which results in higher residual overturning. However, unlike the isopycnal depth shown in Fig. 14a, the sensitivity of the overturning transport to changes in $K$ varies depending on the critical layer depth $z_{c}$. For example, with a deep critical layer, of $z_{c}=2000 \mathrm{~m}$ (black solid line in Fig. 14b), the slope of the line is approximately $-5 \times 10^{-4} \mathrm{~Sv}\left(\mathrm{~m}^{2} \mathrm{~s}^{-1}\right)^{-1}$, indicating almost no sensitivity to changes in $K$, while with a shallow critical layer of $z_{c}=750 \mathrm{~m}$, the streamfunction is highly sensitive to changes in $K$; the slope is approximately $-1 \times 10^{-1} \mathrm{~Sv}\left(\mathrm{~m}^{2} \mathrm{~s}^{-1}\right)^{-1}$, almost three orders of magnitude higher than when $z_{c}=2000 \mathrm{~m}$, although there is a hint of asymptotic behavior in the cases where $z_{c} \leq 1000$ at $K^{\star}$ values higher than about $7500 \mathrm{~m}^{2} \mathrm{~s}^{-1}$. As with the isopycnal depth, the transport in the constant $K$ case is more sensitive to changes in $K$ than the variable diffusivity cases, except for cases with relatively shallow critical layer depths.

We note that the constant diffusivity overturning transport curve (turquoise squares in Fig. 14b) tends to track the $z_{c}=1000 \mathrm{~m}$ case curve reasonably closely. As $z_{c}=1000 \mathrm{~m}$ is approximately what is observed in the Southern Ocean, we can use the concordance between these curves to illustrate the strong reduction in the efficiency of the eddy overturning circulation that occurs with diffusivity suppression. For example, obtaining an eddy overturning that completely balances the mean overturning (i.e., a residual transport of $0 \mathrm{~Sv}$ ) requires a peak diffusivity of $K^{\star} \approx 9500 \mathrm{~m}^{2} \mathrm{~s}^{-1}$ for the vertically varying case (see the upper $x$ axis), while with a constant diffusivity, this transport value can be obtained with a diffusivity of approximately $3000 \mathrm{~m}^{2} \mathrm{~s}^{-1}$. As such, the principle effect of introducing a vertical structure to the eddy diffusivity is to suppress the southward interior transports by eddy fluxes and reduce the efficiency of the eddy overturning.

The details of the effect of suppression on the resulting overturning depend critically on the depth of the critical layer. For example, when the critical layer is very deep $\left(z_{c}=2000 \mathrm{~m}\right)$, the enhanced diffusivity is deeper than the depths with substantial isopycnal slopes, and hence the eddy-induced transport is weak. When the critical layer is shallower, say at 750 or $1000 \mathrm{~m}$, the enhanced diffusivity is found at levels with large isopycnal slopes or IPV gradients and hence can support a substantial eddy overturning. Thus, the resultant residual overturning is sensitive to changes in the value of $K$. As the critical layer depth varies throughout the Southern Ocean (Smith and Marshall 2009; Abernathey et al. 2010; Cole et al. 2015), this result could have important 

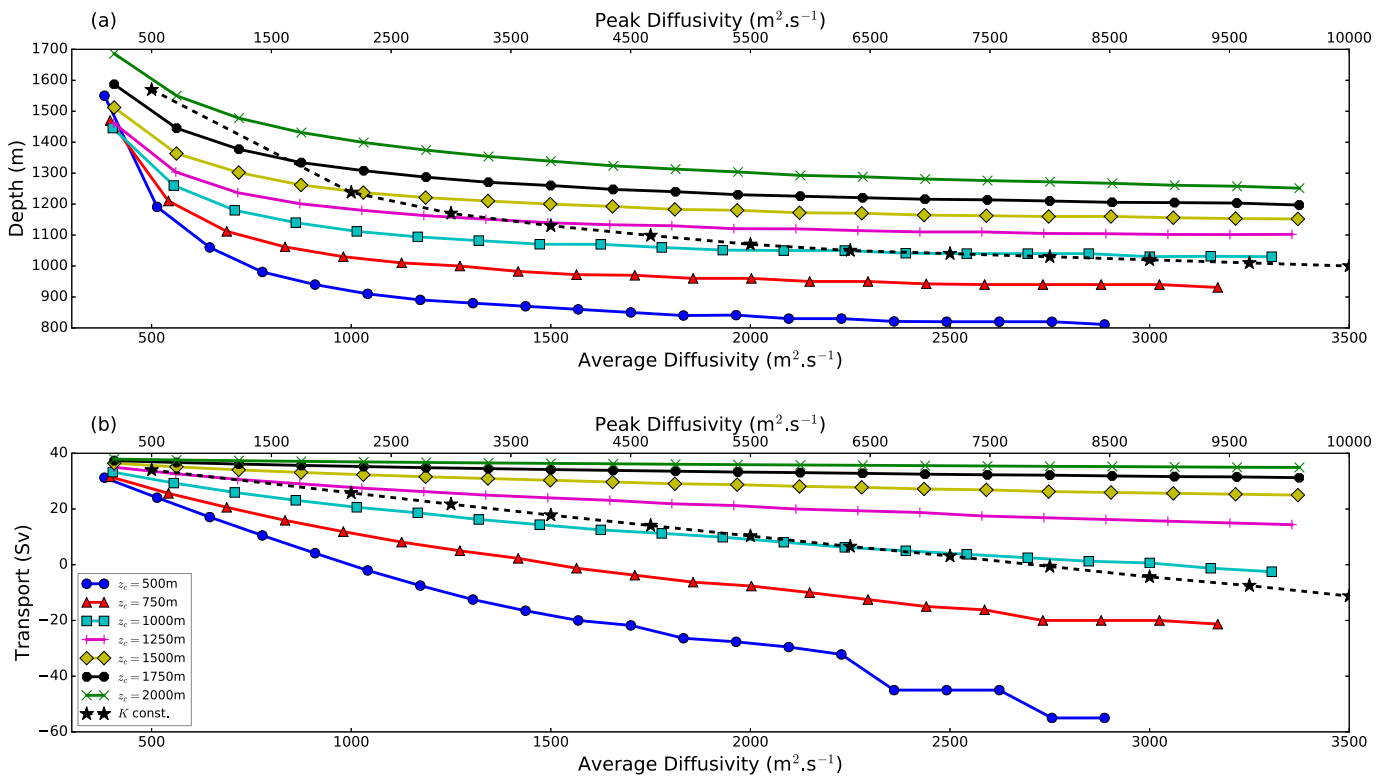

FIG. 14. The response of the stratification and overturning streamfunction to changes in the critical level depth and the eddy diffusivity $K^{\star}$. (a) Depth of the $0.2 \mathrm{~m} \mathrm{~s}^{-1}$ buoyancy surface at $50^{\circ} \mathrm{S}$ and (b) maximum residual overturning transport. Each solid curve corresponds to simulations run with a different critical layer depth $z_{c}$ in Eq. (27) (see legend in Fig. 14b). The dashed black curve (with $\star$ ) corresponds to simulations run with a constant eddy diffusivity. Note the dual abscissa, showing both the (top) peak diffusivity $K^{\star}$ and the (bottom) vertically averaged diffusivity.

implications for the local eddy flux and its parameterization in climate models.

\section{Discussion and conclusions}

In this study, we have investigated how the threedimensional structure of the eddy diffusivity and its suppression by the time-mean flow can influence the MOC in the Southern Ocean. Combining hydrographic observations obtained with satellite altimetry, we have estimated the isopycnal eddy diffusivity $K$ using the framework of Ferrari and Nikurashin (2010) in three dimensions, including the effect of suppression by the time-mean flow. Large values of diffusivity are found in regions downstream of large topographic features, and $K$ is suppressed in regions of strong time-mean flow. When suppression is taken into account, the diffusivity $K$ reaches a peak at the critical layer, which we find to be at about 1000-m depth. Using the estimate of the eddy diffusivity, we are able to estimate the eddy volume flux on an isopycnal as a downgradient diffusion of isopycnal potential vorticity. Together with the ageostrophic Ekman transport, we are able to reconstruct the full upper-ocean meridional circulation in streamwise coordinates.

We have focused on the effect of the suppression of $K$ by the mean flow on the resulting overturning. By comparing reconstructions of the overturning circulation with, and without, the effects of the time-mean flow suppression, we are able to show that the primary effect of the suppressed diffusivity is to dramatically reduce the interior eddy flux, particularly in the intermediate and upper circumpolar deep waters. Reconstructing the eddy overturning using either the unsuppressed diffusivity, or a constant diffusivity, strongly overestimates these interior volume fluxes [at least when compared to the output from the eddy-permitting numerical models, such as those described in Treguier et al. (2007) or Mazloff et al. (2013)]. We find that the parameterized eddy fluxes are zonally asymmetric, being concentrated near, or downstream of, large bathymetric features in regions corresponding to the mixing hot spots or storm tracks identified in previous studies.

One inherent limitation of our observation-based approach is that diffusivity and stratification are intrinsically related, while here we apply differing diffusivity on a fixed stratification. To go beyond this limitation and further explore how the overturning responds to the depth-varying structure of the eddy diffusivity, we use a simple conceptual model of the Southern Ocean, based on that of Marshall and Radko (2003) and Marshall and Radko (2006). We find that, as in the observational part of this study, the addition of a vertical structure to the eddy diffusivity acts to suppress the interior southward eddy transport when compared 
to model runs performed using a vertically constant $K$. The resulting stratification and overturning circulation is also sensitive to the depth of the critical layer. As the critical layer becomes shallower, the overturning transport becomes more sensitive to changes in the magnitude of the peak diffusivity, as the critical layer and its associated region of high-eddy diffusivities are more likely to coincide with regions with large isopycnal slopes or potential vorticity gradients.

The principle result of this study is that the horizontal mixing suppression due to the Antarctic Circumpolar Current is critical in shaping the interior Southern Ocean overturning circulation, modulating the efficiency of the resulting eddy overturning circulation. We find that the details of the overturning and interior stratification are sensitive to both the magnitude of $K$ and also the depth of the critical layer, which both depend on a subtle balance between eddy characteristics and mean flow. The corollary of this result is that in order to reconstruct an overturning circulation using a downgradient parameterization correctly representing the interior suppression of eddy diffusivity by the mean flow is crucial. The fact that the vertical structure of the diffusivity plays such an important role in parameterized eddy flux may have important implications for coarseresolution ocean models used for long-period climate studies, as these models still rely on downgradient turbulence closures such as Gent-McWilliams. Further research will explore the role of the vertical diffusivity structure in the response to climate change as well as refining our estimate of the overturning circulation through the use of new data, parameterizations, and analysis techniques.

Acknowledgments. The authors thank Dhruv Balwada, Jessica Masich, Andreas Klocker, and Christopher Roach for useful discussions and Christopher Roach for helpfully providing the diffusivity data from Roach et al. (2016) for comparison with our calculations. We also thank two anonymous reviewers for their comments on an earlier version of this manuscript. C. C. was supported by an NSF Division of Ocean Sciences postdoctoral fellowship Grant 1521508. J. B. S. received support from Agence Nationale de la Recherche (ANR) ANR-12-PDOC-0001.

\section{APPENDIX A}

\section{Data Availability}

All interpolated fields used in this study, including the estimates of the suppressed and unsuppressed eddy diffusivity, the neutral density, the approximate isopycnal geostrophic streamfunction and its variance, and the isopycnal potential vorticity, are available online for download in NetCDF format (available online at https://dx.doi.org/10.5061/dryad.55bp8).

The output is provided annually. Additionally, the first two seasonal harmonics are estimated and are included in the output.

\section{APPENDIX B}

\section{Numerical Method for the Conceptual Model}

The primary equation that needs to be solved for the implementation of the conceptual TEM model [Eq. (16)] has the form

$$
A\left(\eta, b, \Psi^{\mathrm{res}}\right) \frac{\partial \bar{b}}{\partial \eta}+B\left(\eta, b, \Psi^{\mathrm{res}}\right) \frac{\partial \bar{b}}{\partial z}=0,
$$

where $A$ and $B$ are coefficients that are functions of the surface wind stress and the residual overturning streamfunction, together with Dirichlet boundary conditions for $\bar{b}$ at $z=0$ and $\eta=L_{\eta}$. Using the method of characteristics, this linear partial differential equation can be written as the set of coupled ordinary differential equations:

$$
\begin{aligned}
\frac{d \eta}{d \ell} & =A\left(\eta, \bar{b}, \Psi^{\mathrm{res}}\right), \\
\frac{d z}{d \ell} & =B\left(\eta, \bar{b}, \Psi^{\mathrm{res}}\right), \\
\frac{d \bar{b}}{d \ell} & =0, \quad \text { and } \\
\frac{d \Psi^{\mathrm{res}}}{d \ell} & =0,
\end{aligned}
$$

where $\ell$ is the distance along the characteristic curve, which, in this case, is simply the isopycnal $\bar{b}$, together with the boundary conditions

$$
\begin{gathered}
\bar{b}(\eta, z=0)=g(\eta), \quad \text { and } \\
\bar{b}\left(\eta=L_{\eta}, z\right)=f(\eta) .
\end{gathered}
$$

Equations (B2)-(B4) are solved using a fourth-order Runge-Kutta method. Boundary conditions are imposed using the shooting method; using large initial guesses of $\Psi^{\text {res }}= \pm 100 \mathrm{~Sv}$ and starting at $z=0$, Eqs. (B2)-(B4) are integrated until $y=L_{\eta}$. We then compare the depth of the isopycnal to the depth of that isopycnal expected from the boundary conditions [(B7)] and apply the bisection method to systematically adjust the guess of $\Psi^{\mathrm{res}}$ until convergence to a predefined error tolerance (here, $5 \mathrm{~m}$ ). 
Computer code to implement this model, written in the open-source Python programming language, is available under an open-source MIT license from CC's Github account (https://github.com/ChrisC28).

\section{REFERENCES}

Abernathey, R., J. Marshall, M. Mazloff, and E. Shuckburgh, 2010: Enhancement of mesoscale eddy stirring at steering levels in the Southern Ocean. J. Phys. Oceanogr., 40, 170-184, doi:10.1175/2009JPO4201.1.

_, _ and D. Ferreira, 2011: The dependence of Southern Ocean meridional overturning on wind stress. J. Phys. Oceanogr., 41, 2261-2278, doi:10.1175/JPO-D-11-023.1.

- D. Ferreira, and A. Klocker, 2013: Diagnostics of isopycnal mixing in a circumpolar channel. Ocean Modell., 72, 1-16, doi:10.1016/j.ocemod.2013.07.004.

Bates, M., R. Tulloch, J. Marshall, and R. Ferrari, 2014: Rationalizing the spatial distribution of mesoscale eddy diffusivity in terms of mixing length theory. J. Phys. Oceanogr., 44, 1523-1540, doi:10.1175/JPO-D-13-0130.1.

Boyer, T., and Coauthors, 2009: World Ocean Database 2009. NOAA Atlas NESDIS 66, $216 \mathrm{pp}$.

Chapman, C. C., A. M. Hogg, A. E. Kiss, and S. R. Rintoul, 2015: The dynamics of Southern Ocean storm tracks. J. Phys. Oceanogr., 45, 884-903, doi:10.1175/JPO-D-14-0075.1.

Chelton, D. B., R. A. deSzoeke, M. G. Schlax, K. E. Naggar, and N. Siwertz, 1998: Geographical variability of the first baroclinic Rossby radius of deformation. J. Phys. Oceanogr., 28, 433-460, doi:10.1175/1520-0485(1998)028<0433 GVOTFB $>2.0 . \mathrm{CO} ; 2$.

Chien, C.-Y., 2009: Comparison of wind speed and wind stress in the Southern Ocean. M.S. thesis, Department of Oceanography, Florida State University, 45 pp. [Available online at http://fsu.digital.flvc.org/islandora/object/ fsu \%3A182061.]

Cole, S. T., C. Wortham, E. Kunze, and W. B. Owens, 2015: Eddy stirring and horizontal diffusivity from Argo float observations: Geographic and depth variability. Geophys. Res. Lett., 42, 3989-3997, doi:10.1002/2015GL063827.

Danabasoglu, G., and J. Marshall, 2007: Effects of vertical variations of thickness diffusivity in an ocean general circulation model. Ocean Modell., 18, 122-141, doi:10.1016/ j.ocemod.2007.03.006

de Szoeke, R. A., and M. D. Levine, 1981: The advective flux of heat by mean geostrophic motions in the Southern Ocean. Deep-Sea Res., 28A, 1057-1085, doi:10.1016/ 0198-0149(81)90048-0.

Döös, K., and D. J. Webb, 1994: The Deacon cell and the other meridional cells of the Southern Ocean. J. Phys. Oceanogr., 24, 429-442, doi:10.1175/1520-0485(1994)024<0429: TDCATO $>2.0 . C O ; 2$.

Downes, S. M., and A. M. Hogg, 2013: Southern Ocean circulation and eddy compensation in CMIP5 models. J. Climate, 26 7198-7220, doi:10.1175/JCLI-D-12-00504.1.

Dufour, C. O., J. L. Sommer, J. D. Zika, M. Gehlen, J. C. Orr, P. Mathiot, and B. Barnier, 2012: Standing and transient eddies in the response of the Southern Ocean meridional overturning to the southern annular mode. J. Climate, 25, 6958-6974, doi:10.1175/JCLI-D-11-00309.1.

_ - and Coauthors, 2015: Role of mesoscale eddies in crossfrontal transport of heat and biogeochemical tracers in the
Southern Ocean. J. Phys. Oceanogr., 45, 3057-3081, doi:10.1175/JPO-D-14-0240.1.

Dutton, J., 1986: Dynamics of Atmospheric Motion. Dover Publications, $617 \mathrm{pp}$.

Faure, V., and K. Speer, 2012: Deep circulation in the eastern South Pacific Ocean. J. Mar. Res., 70, 748-778, doi:10.1357/ 002224012806290714.

Ferrari, R., and M. Nikurashin, 2010: Suppression of eddy diffusivity across jets in the Southern Ocean. J. Phys. Oceanogr., 40, 1501-1519, doi:10.1175/2010JPO4278.1.

Ferreira, D., J. Marshall, and P. Heimbach, 2005: Estimating eddy stresses by fitting dynamics to observations using a residualmean ocean circulation model and its adjoint. J. Phys. Oceanogr., 35, 1891-1910, doi:10.1175/JPO2785.1.

Gent, P. R., and J. C. McWilliams, 1990: Isopycnal mixing in ocean circulation models. J. Phys. Oceanogr., 20, 150-155, doi:10.1175/1520-0485(1990)020<0150:IMIOCM >2.0.CO;2.

Holloway, G., 1986: Estimation of oceanic eddy transports from satellite altimetry. Nature, 323, 243-244, doi:10.1038/323243a0.

Jackett, D. R., and T. J. McDougall, 1997: A neutral density variable for the world's oceans. J. Phys. Oceanogr., 27, 237-263, doi:10.1175/1520-0485(1997)027<0237:ANDVFT>2.0.CO;2.

Johnson, G. C., and H. L. Bryden, 1989: On the size of the Antarctic Circumpolar Current. Deep-Sea Res., 36A, 39-53, doi:10.1016/ 0198-0149(89)90017-4.

Kalnay, E., and Coauthors, 1996: The NCEP/NCAR 40-Year Reanalysis Project. Bull. Amer. Meteor. Soc., 77, 437-471, doi:10.1175/1520-0477(1996)077<0437:TNYRP>2.0.CO;2.

Karsten, R. H., and J. Marshall, 2002: Constructing the residual circulation of the ACC from observations. J. Phys. Oceanogr., 32, 3315-3327, doi:10.1175/1520-0485(2002)032<3315: CTRCOT $>2.0 . \mathrm{CO}$;.

Keffer, T., and G. Holloway, 1988: Estimating Southern Ocean eddy flux of heat and salt from satellite altimetry. Nature, $\mathbf{3 3 2}$, 624-626, doi:10.1038/332624a0.

Killworth, P. D., 1997: On the parameterization of eddy transfer. Part I. Theory. J. Mar. Res., 55, 1171-1197, doi:10.1357/ 0022240973224102 .

Klocker, A., and R. Abernathey, 2014: Global patterns of mesoscale eddy properties and diffusivities. J. Phys. Oceanogr., 44, 1030-1046, doi:10.1175/JPO-D-13-0159.1.

— , and D. P. Marshall, 2014: Advection of baroclinic eddies by depth mean flow. Geophys. Res. Lett., 41, 3517-3521, doi:10.1002/2014GL060001.

Koh, T.-Y., and R. A. Plumb, 2004: Isentropic zonal average formalism and the near-surface circulation. Quart. J. Roy. Meteor. Soc., 130, 1631-1653, doi:10.1256/qj.02.219.

Kosempa, M., and D. P. Chambers, 2014: Southern Ocean velocity and geostrophic transport fields estimated by combining Jason altimetry and Argo data. J. Geophys. Res. Oceans, 119, 4761-4776, doi:10.1002/2014JC009853.

Kuo, A., R. A. Plumb, and J. Marshall, 2005: Transformed Eulerian-mean theory. Part II: Potential vorticity homogenization and the equilibrium of a wind- and buoyancy-driven zonal flow. J. Phys. Oceanogr., 35, 175-187, doi:10.1175/ JPO-2670.1.

LaCasce, J. H., R. Ferrari, J. Marshall, R. Tulloch, D. Balwada, and K. Speer, 2014: Float-derived isopycnal diffusivities in the DIMES experiment. J. Phys. Oceanogr., 44, 764-780, doi:10.1175/JPO-D-13-0175.1.

Lenn, Y.-D., and T. K. Chereskin, 2009: Observations of Ekman currents in the Southern Ocean. J. Phys. Oceanogr., 39, 768-779, doi:10.1175/2008JPO3943.1. 
Le Quéré, C., and Coauthors, 2007: Saturation of the southern ocean $\mathrm{CO}_{2}$ sink due to recent climate change. Science, 316, 1735-1738, doi:10.1126/science.1136188.

Li, M., J. Liu, Z. Wang, H. Wang, Z. Zhang, L. Zhang, and Q. Yang, 2013: Assessment of sea surface wind from NWP reanalyses and satellites in the Southern Ocean. J. Atmos. Oceanic Technol., 30, 1842-1853, doi:10.1175/JTECH-D-12-00240.1.

MacCready, P., and P. B. Rhines, 2001: Meridional transport across a zonal channel: Topographic localization. J. Phys. Oceanogr., 31, 1427-1439, doi:10.1175/1520-0485(2001)031<1427: MTAAZC $>2.0 . \mathrm{CO} ; 2$.

Marshall, D. P., R. G. Williams, and M.-M. Lee, 1999: The relation between eddy-induced transport and isopycnic gradients of potential vorticity. J. Phys. Oceanogr., 29, 1571-1578, doi:10.1175/1520-0485(1999)029<1571:TRBEIT>2.0.CO;2.

Marshall, J., and T. Radko, 2003: Residual-mean solutions for the Antarctic Circumpolar Current and its associated overturning circulation. J. Phys. Oceanogr., 33, 2341-2354, doi:10.1175/ 1520-0485(2003)033<2341:RSFTAC >2.0.CO;2.

$\longrightarrow$, and - 2006: A model of the upper branch of the meridional overturning of the Southern Ocean. Prog. Oceanogr., 70, 331-345, doi:10.1016/j.pocean.2006.07.004.

—_, and K. Speer, 2012: Closure of the meridional overturning circulation through Southern Ocean upwelling. Nat. Geosci., 5, 171-180, doi:10.1038/ngeo1391.

—, D. Olbers, H. Ross, and D. Wolf-Gladrow, 1993: Potential vorticity constraints on the dynamics and hydrography of the Southern Ocean. J. Phys. Oceanogr., 23, 465-487, doi:10.1175/ 1520-0485(1993)023<0465:PVCOTD > 2.0.CO;2.

- E. Shuckburgh, H. Jones, and C. Hill, 2006: Estimates and implications of surface eddy diffusivity in the Southern Ocean derived from tracer transport. J. Phys. Oceanogr., 36, 1806-1821, doi:10.1175/JPO2949.1.

Mazloff, M. R., 2008: The Southern Ocean meridional overturning circulation as diagnosed from an eddy permitting state estimate. Ph.D. thesis, Massachusetts Institute of Technology-Woods Hole Oceanographic Institution Joint Program, 127 pp.

- , R. Ferrari, and T. Schneider, 2013: The force balance of the Southern Ocean meridional overturning circulation. J. Phys. Oceanogr., 43, 1193-1208, doi:10.1175/JPO-D-12-069.1.

McCaffrey, K., B. Fox-Kemper, and G. Forget, 2015: Estimates of ocean macroturbulence: Structure function and spectral slope from Argo profiling floats. J. Phys. Oceanogr., 45, 1773-1793, doi:10.1175/JPO-D-14-0023.1.

McDougall, T. J., 1989: Streamfunctions for the lateral velocity vector in a compressible ocean. J. Mar. Res., 47, 267-284, doi:10.1357/002224089785076271.

—_, and A. Klocker, 2010: An approximate geostrophic streamfunction for use in density surfaces. Ocean Modell., 32, 105-117, doi:10.1016/j.ocemod.2009.10.006.

— the Gibbs Seawater (GSW) oceanographic toolbox. SCOR/ IAPSO WG127, 28 pp. [Available online at www.teos-10.org/ pubs/Getting_Started.pdf.]

Meredith, M. P., A. C. N. Garabato, A. M. Hogg, and R. Farneti, 2012: Sensitivity of the overturning circulation in the Southern Ocean to decadal changes in wind forcing. J. Climate, 25, 99-110, doi:10.1175/2011JCLI4204.1.

Naveira Garabato, A. C., D. Stevens, A. Watson, and W. Roether, 2007: Short-circuiting of the overturning circulation in the Antarctic Circumpolar Current. Nature, 447, 194-197, doi:10.1038/nature05832.
- R. Ferrari, and K. L. Polzin, 2011: Eddy stirring in the Southern Ocean. J. Geophys. Res., 116, C09019, doi:10.1029/ 2010JC006818.

Plumb, R. A., and R. Ferrari, 2005: Transformed Eulerian-mean theory. Part I: Nonquasigeostrophic theory for eddies on a zonal-mean flow. J. Phys. Oceanogr., 35, 165-174, doi:10.1175/ JPO-2669.1.

Pujol, M.-I., Y. Faugère, G. Taburet, S. Dupuy, C. Pelloquin, M. Ablain, and N. Picot, 2016: DUACS DT2014: The new multi-mission altimeter data set reprocessed over 20 years. Ocean Sci., 12, 1067-1090, doi:10.5194/os-12-1067-2016.

Ridgway, K., J. Dunn, and J. Wilkin, 2002: Ocean interpolation by four-dimensional weighted least squares-Application to the waters around Australasia. J. Atmos. Oceanic Technol., 19, 1357-1375, doi:10.1175/1520-0426(2002)019<1357:OIBFDW>2.0.CO;2.

Riser, S. C., and Coauthors, 2016: Fifteen years of ocean observations with the global Argo array. Nat. Climate Change, 6 , 145-153, doi:10.1038/nclimate2872.

Roach, C. J., D. Balwada, and K. Speer, 2016: Horizontal mixing in the Southern Ocean from Argo float trajectories. J. Geophys. Res. Oceans, 121, 5570-5586, doi:10.1002/2015JC011440.

Roberts, M. J., and D. P. Marshall, 2000: On the validity of downgradient eddy closures in ocean models. J. Geophys. Res., 105, 28 613-28 627, doi:10.1029/1999JC000041.

Roemmich, D., and Coauthors, 2009: The Argo program: Observing the global ocean with profiling floats. Oceanography, 22, 34-43, doi:10.5670/oceanog.2009.36.

Roquet, F., and Coauthors, 2013: Estimates of the Southern Ocean general circulation improved by animal-borne instruments. Geophys. Res. Lett., 40, 6176-6180, doi:10.1002/ 2013 GL058304.

— , and Coauthors, 2014: A southern Indian Ocean database of hydrographic profiles obtained with instrumented elephant seals. Sci. Data, 1, 140028, doi:10.1038/sdata.2014.28.

Sallée, J. B., K. Speer, R. Morrow, and R. Lumpkin, 2008: An estimate of Lagrangian eddy statistics and diffusion in the mixed layer of the Southern Ocean. J. Mar. Res., 66, 441-463, doi: $10.1357 / 002224008787157458$.

_- E. Shuckburgh, N. Bruneau, A. Meijers, T. Bracegirdle, Z. Wang, and T. Roy, 2013: Assessment of southern ocean water mass circulation and characteristics in CMIP5 models: Historical bias and forcing response. J. Geophys. Res. Oceans, 118, 1830-1844, doi:10.1002/jgrc.20135.

Schmidtko, S., G. C. Johnson, and J. M. Lyman, 2013: MIMOC: A global monthly isopycnal upper-ocean climatology with mixed layers. J. Geophys. Res. Oceans, 118, 1658-1672, doi:10.1002/ jgrc. 20122.

Shuckburgh, E., H. Jones, J. Marshall, and C. Hill, 2009: Robustness of an effective diffusivity diagnostic in oceanic flows. J. Phys. Oceanogr., 39, 1993-2009, doi:10.1175/2009JPO4122.1.

Smith, K. S., 2007: The geography of linear baroclinic instability in Earth's oceans. J. Mar. Res., 65, 655-683, doi:10.1357/ 002224007783649484.

_ , and J. Marshall, 2009: Evidence for enhanced eddy mixing at middepth in the southern ocean. J. Phys. Oceanogr., 39, 50-69, doi:10.1175/2008JPO3880.1.

Sokolov, S., and S. R. Rintoul, 2007: Multiple jets of the Antarctic Circumpolar Current south of Australia. J. Phys. Oceanogr., 37, 1394-1412, doi:10.1175/JPO3111.1.

Ssalto/Duacs, 2014: Ssalto/Duacs gridded sea level anomalies. Copernicus Marine and Environment Monitoring Services, accessed 15 April 2016. [Available online at http://marine. copernicus.eu/web/69-interactive-catalogue.php.] 
Talley, L. D., J. L. Reid, and P. E. Robbins, 2003: Data-based meridional overturning streamfunctions for the global ocean. J. Climate, 16, 3213-3226, doi:10.1175/1520-0442(2003)016<3213: DMOSFT $>2.0 . \mathrm{CO} ; 2$.

Thompson, A. F., and J.-B. Sallée, 2012: Jets and topography: Jet transitions and the impact on transport in the Antarctic Circumpolar Current. J. Phys. Oceanogr., 42, 956-972, doi:10.1175/JPO-D-11-0135.1.

_ - and A. C. Naveira Garabato, 2014: Equilibration of the Antarctic Circumpolar Current by standing meanders. J. Phys. Oceanogr., 44, 1811-1828, doi:10.1175/JPO-D-13-0163.1.

Treguier, A. M., I. M. Held, and V. D. Larichev, 1997: Parameterization of quasigeostrophic eddies in primitive equation ocean models. J. Phys. Oceanogr., 27, 567-580, doi:10.1175/ 1520-0485(1997)027<0567:POQEIP>2.0.CO;2.

—, M. H. England, S. R. Rintoul, G. Madec, J. Le Sommer, and J.-M. Molines, 2007: Southern Ocean overturning across streamlines in an eddying simulation of the Antarctic Circumpolar Current. Ocean Sci., 3, 491-507, doi:10.5194/ os-3-491-2007.

Tulloch, R., and Coauthors, 2014: Direct estimate of lateral eddy diffusivity upstream of Drake Passage. J. Phys. Oceanogr., 44, 2593-2616, doi:10.1175/JPO-D-13-0120.1.
Viebahn, J., and C. Eden, 2010: Towards the impact of eddies on the response of the southern ocean to climate change. Ocean Modell., 34, 150-165, doi:10.1016/j.ocemod.2010.05.005.

— , and - 2012: Standing eddies in the meridional overturning circulation. J. Phys. Oceanogr., 42, 1486-1508, doi:10.1175/JPO-D-11-087.1.

Ward, M. L., and A. M. Hogg, 2011: Establishment of momentum balance by form stress in a wind-driven channel. Ocean Modell., 40, 133-146, doi:10.1016/j.ocemod.2011.08.004.

Wardle, R., and J. Marshall, 2000: Representation of eddies in primitive equation models by a PV flux. J. Phys. Oceanogr., 30, 2481-2503, doi:10.1175/1520-0485(2000)030<2481: ROEIPE $>2.0 . \mathrm{CO} ; 2$.

Williams, R. G., C. Wilson, and C. W. Hughes, 2007: Ocean and atmosphere storm tracks: The role of eddy vorticity forcing. J. Phys. Oceanogr., 37, 2267-2289, doi:10.1175/JPO3120.1.

Wilson, C., and R. G. Williams, 2004: Why are eddy fluxes of potential vorticity difficult to parameterize? J. Phys. Oceanogr., 34, 142-155, doi:10.1175/1520-0485(2004)034<0142: WAEFOP $>2.0 . \mathrm{CO} ; 2$

Zika, J. D., and Coauthors, 2013: Vertical eddy fluxes in the Southern Ocean. J. Phys. Oceanogr., 43, 941-955, doi:10.1175/ JPO-D-12-0178.1. 